\title{
Selective antagonism of muscarinic receptors is neuroprotective in peripheral neuropathy
}

\author{
Nigel A. Calcutt, ${ }^{1}$ Darrell R. Smith, ${ }^{2}$ Katie Frizzi, ${ }^{1}$ Mohammad Colam Sabbir, ${ }^{2}$ Subir K. Roy Chowdhury, ${ }^{2}$ Teresa Mixcoatl-Zecuatl, \\ Ali Saleh, ${ }^{2}$ Nabeel Muttalib, ${ }^{1}$ Randy Van der Ploeg, ${ }^{2}$ Joseline Ochoa, ${ }^{1}$ Allison Gopaul, ${ }^{1}$ Lori Tessler, ${ }^{2}$ Jürgen Wess, ${ }^{3}$ \\ Corinne G. Jolivalt, ${ }^{1}$ and Paul Fernyhough ${ }^{2,4}$ \\ 'Department of Pathology, UCSD, La Jolla, California, USA. ²Division of Neurodegenerative Disorders, St. Boniface Hospital Research Centre, Winnipeg, Manitoba, Canada. ${ }^{3}$ Molecular Signaling Section, \\ Laboratory of Bioorganic Chemistry, National Institute of Diabetes and Digestive and Kidney Diseases, NIH, Bethesda, Maryland, USA. ${ }^{4}$ Department of Pharmacology and Therapeutics, University of \\ Manitoba, Winnipeg, Manitoba, Canada.
}

\begin{abstract}
Sensory neurons have the capacity to produce, release, and respond to acetylcholine (ACh), but the functional role of cholinergic systems in adult mammalian peripheral sensory nerves has not been established. Here, we have reported that neurite outgrowth from adult sensory neurons that were maintained under subsaturating neurotrophic factor conditions operates under cholinergic constraint that is mediated by muscarinic receptor-dependent regulation of mitochondrial function via AMPK. Sensory neurons from mice lacking the muscarinic $A C h$ type 1 receptor $\left(M_{1} R\right)$ exhibited enhanced neurite outgrowth, confirming the role of $M_{1} R$ in tonic suppression of axonal plasticity. $M_{1} R$-deficient mice made diabetic with streptozotocin were protected from physiological and structural indices of sensory neuropathy. Pharmacological blockade of $M_{1} R$ using specific or selective antagonists, pirenzepine, VU0255035, or muscarinic toxin 7 (MT7) activated AMPK and overcame diabetesinduced mitochondrial dysfunction in vitro and in vivo. These antimuscarinic drugs prevented or reversed indices of peripheral neuropathy, such as depletion of sensory nerve terminals, thermal hypoalgesia, and nerve conduction slowing in diverse rodent models of diabetes. Pirenzepine and MT7 also prevented peripheral neuropathy induced by the chemotherapeutic agents dichloroacetate and paclitaxel or HIV envelope protein gp120. As a variety of antimuscarinic drugs are approved for clinical use against other conditions, prompt translation of this therapeutic approach to clinical trials is feasible.
\end{abstract}

\section{Introduction}

The innervation territory of intraepidermal nerve fibers (IENF) within the skin is plastic and maintained through a combination of collateral sprouting and regeneration that is regulated partly by neurotrophic factors (1). Distal dying-back or degeneration of nerve fibers is observed in many axonopathic diseases, including diabetic neuropathy, chemotherapy-induced peripheral neuropathy (CIPN), Friedreich ataxia, Charcot-Marie-Tooth disease type 2, and HIV-associated distal-symmetric neuropathy. There are no therapies for any of these diseases, all of which display some degree of mitochondrial dysfunction (2-4). This is pertinent, as the growth-cone motility required to maintain fields of innervation consumes $50 \%$ of ATP supplies in neurons due to high rates of actin treadmilling (5). Maintenance of plastic innervation therefore requires high consumption of ATP for growthcone motility and maintenance of terminals and synapses (6, 7). Unmyelinated axons are also more energetically demanding than myelinated axons, consuming 2.5- to 10-fold more energy per action potential (8). Mitochondria are known to concentrate

Conflict of interest: P. Fernyhough and N.A. Calcutt declare they are directors and shareholders in WinSanTor Inc., which has licensed intellectual property from the University of Manitoba and UCSD. This intellectual property includes data presented in the current manuscript.

Submitted: May 11, 2016; Accepted: November 22, 2016.

Reference information: J Clin Invest. 2017;127(2):608-622.

https://doi.org/10.1172/JCl88321 in regions of high metabolic demand (9), and sensory terminal boutons are packed with mitochondria (10).

Our work in rodent models of type 1 and 2 diabetes exhibiting neuropathy demonstrates that hyperglycemia triggers nutrient excess in neurons that, in turn, mediates a phenotypic change in mitochondria through alteration of the AMPK/peroxisome proliferator-activated receptor $\gamma$ coactivator- $1 \alpha(\mathrm{PGC}-1 \alpha)$ signaling axis $(4,11)$. This vital energy-sensing metabolic pathway modulates mitochondrial function, biogenesis, and regeneration (12). There is accumulating evidence that stimulation of the AMPK/PGC- $1 \alpha$ axis in neurons promotes improved mitochondrial function and regeneration $(4,13)$. For example, the AMPK activator resveratrol enhances neurite outgrowth (14), while augmented AMPK signaling maintains outer retina synapses (15) and directs mitochondria to axons to drive branching in cerebellar granule neurons (16). Upregulation of PGC- $1 \alpha$ is protective against oxidative stress in hippocampal neurons (17) and prevents mutant Parkin-related degeneration in dopaminergic neurons (18). In the context of diabetes, the bioenergetic phenotype of mitochondria in dorsal root ganglia-derived (DRG-derived) sensory neurons is characterized by inner membrane depolarization, reduced expression of respiratory chain components, and suboptimal spare respiratory capacity $(4,11)$ without remarkable ultrastructural alterations (19). Activation of AMPK by resveratrol protected mitochondrial function and peripheral nerve structure and function in rodent models of both type 1 and type 2 diabetes (11). 
A

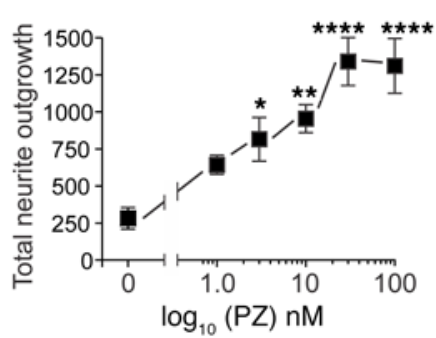

C

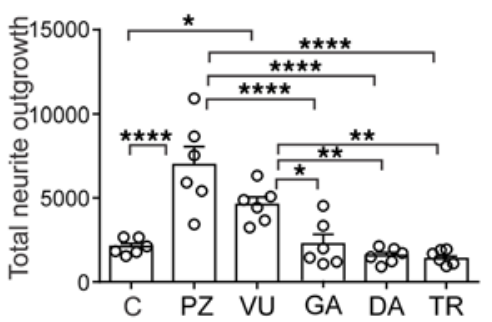

B
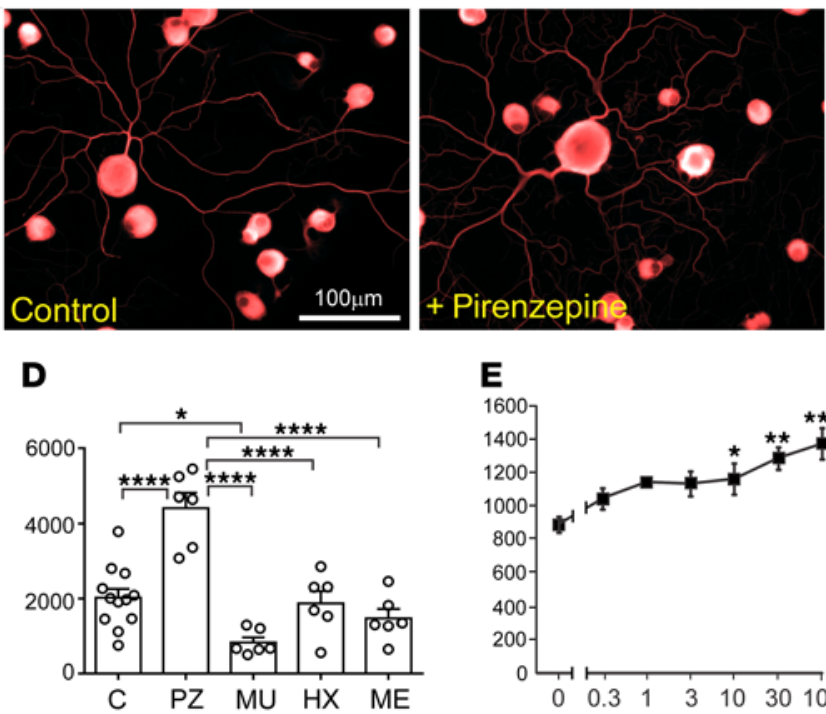

E

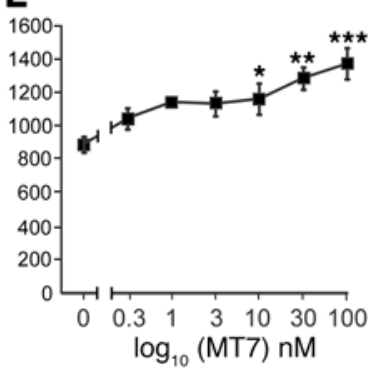

$\mathbf{F}$

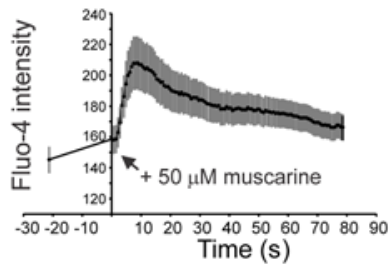

G

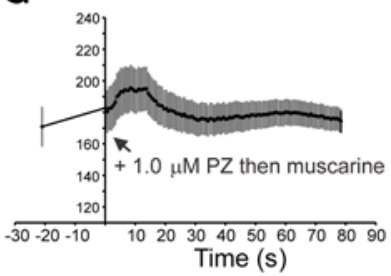

H

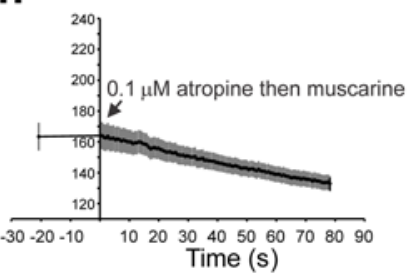

Figure 1. The $M, R$ regulates neurite outgrowth from adult sensory neurons. (A) Neurons derived from normal rats were cultured for 24 hours and total neurite outgrowth presented as mean \pm SEM of $n=7$ replicate cultures. ${ }^{*} P<0.05$; ${ }^{* *} P<0.01$; ${ }^{* * *} P<0.0001$ vs. 0 by 1 -way ANOVA with Dunnett's posthoc test. PZ, pirenzepine. (B) $\beta$-tubulin III-immunostained sensory neurons that were untreated (control) or treated with $1 \mu \mathrm{M}$ pirenzepine for 24 hours. Scale bar: $100 \mu \mathrm{m}$. (C) Total neurite outgrowth when exposed to $1 \mu \mathrm{M}$ pirenzepine, $30 \mathrm{nM}$ VU0255035 (VU), $1 \mu \mathrm{M}$ darafenacin (DA), $1 \mu \mathrm{M}$ gallamine (GA), and $1 \mu \mathrm{M}$ tropicamide (TR) or (D) $1 \mu \mathrm{M}$ pirenzepine, $10 \mu \mathrm{M}$ muscarine (MU), $20 \mu \mathrm{M}$ hexamethonium (HX), and $50 \mu \mathrm{M}$ mecamylamine (ME). Open circles indicate individual data points. C, control. (E) Dose-response curve for effect of MT7 on total neurite outgrowth. Data points represent mean \pm SEM of $n=6$-12 replicate cultures. Within an experiment, ${ }^{*} P<0.05$; ${ }^{* *} P<0.01 ;{ }^{* *} P<0.001$; ${ }^{* * * *} P<0.0001$ by 1-way ANOVA with Dunnett's (in E vs. untreated) or Tukey's (in $\mathbf{C}$ and $\mathbf{D}$ ) post-hoc test. Sensory neurons were loaded with fluo-4 and transient changes in intracellular calcium concentration were measured in response to (F) $50 \mu \mathrm{M}$ muscarine ( $n=54$ neurons), (C) pretreated with $1 \mu \mathrm{M}$ pirenzepine, then treated with muscarine ( $n=69$ neurons), and (H) pretreated with $0.1 \mu \mathrm{M}$ atropine, then treated with muscarine $(n=78$ neurons). Group mean \pm SEM are shown.

In an effort to identify molecules capable of enhancing peripheral nerve repair, we screened compounds for their ability to enhance neurite outgrowth in adult sensory neurons using the NIH/Juvenile Diabetes Research Foundation (JDRF) Custom Collection (maintained by Micro Source Discovery Systems Inc.). The primary screen utilized sensory neurons derived from DRG of adult rats, with subsequent hits advanced to neurons derived from rat models of type 1 (streptozotocin [STZ]) and type 2 (Zucker diabetic fatty [ZDF]) diabetes. A number of molecules with antimuscarinic properties were identified as promoting neurite outgrowth in this system. Prior work in neurons from Aplysia and Xenopus showed both spontaneous and evoked release of quantal packets of acetylcholine (ACh) from growth cones. ACh modulated $\mathrm{Ca}^{2+}$-dependent motility via nicotinic and muscarinic receptors, with nicotinic signaling being positive for growth and muscarinic signaling negative $(20,21)$. Studies in embryonic sensory neurons have also demonstrated that ACh signaling through muscarinic receptors, and associated mobilization of $\mathrm{Ca}^{2+}$ from internal stores, acts as a regulator of growth-cone motility during devel- opment $(22,23)$. In mammals, cell bodies of sensory neurons synthesize and secrete ACh (24), express a peripheral form of choline acetyltransferase (pChAT), exhibit ChAT activity, have low acetylcholinesterase (AChE) activity, and express multiple muscarinic receptors including muscarinic Ach type 1 receptor $\left(M_{1} R\right)$ (25-27). Together, these findings support the credibility of an endogenous cholinergic system that tonically suppresses neurite outgrowth in adult mammalian neuronal cells.

The aim of the current study was to determine the mechanism by which antimuscarinic compounds enhance neurite outgrowth and to translate findings into a therapeutic approach that could prevent or reverse peripheral neuropathy in a range of in vitro and in vivo models. Our data introduce selective or specific antimuscarinic drugs as a therapeutic approach for preventing and reversing sensory neuropathy in a variety of disease states of the PNS.

\section{Results}

Muscarinic antagonists selective or specific for $M_{1} R$ enhance neurite outgrowth. A preliminary screen (summarized in Supplemental Figures 1 and 2; supplemental material available online with this 
A

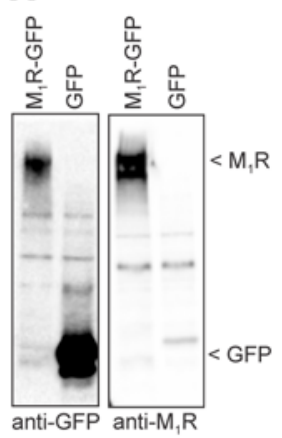

C
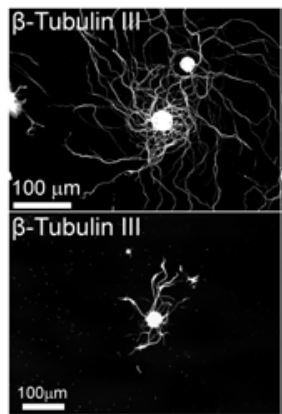

E

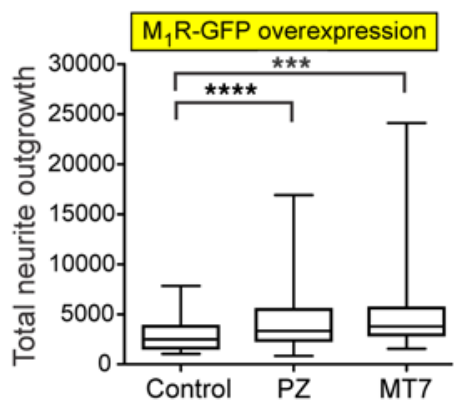

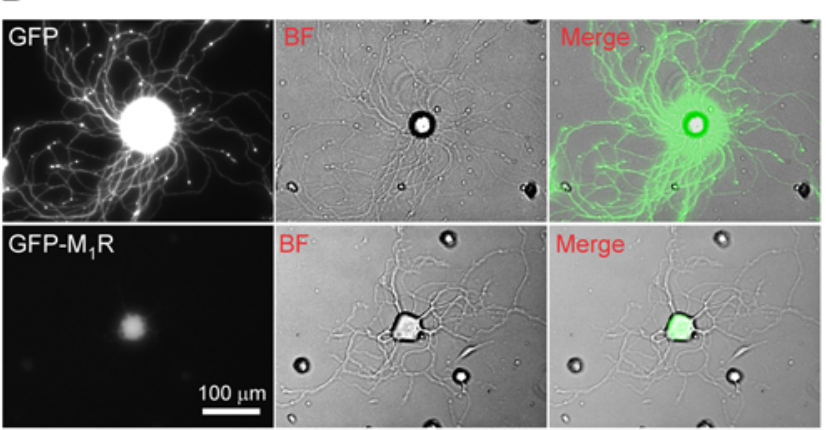

D

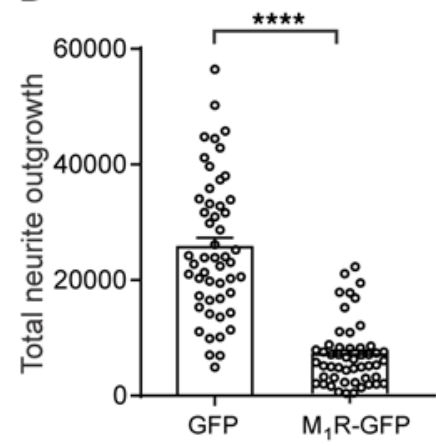

F

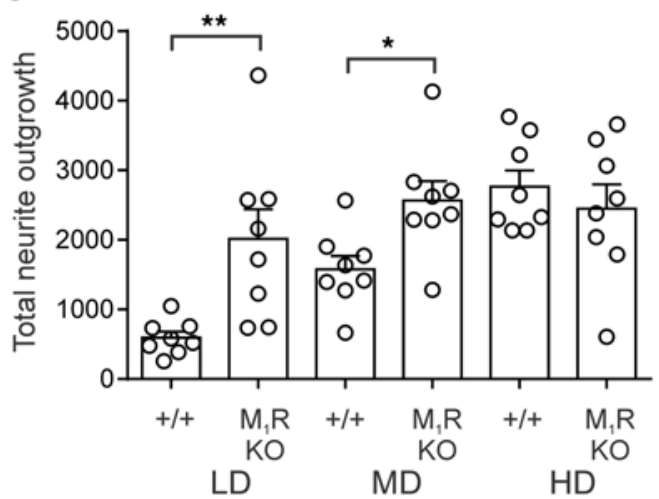

Figure 2. Overexpression of GFP-M,R fusion protein inhibits neurite outgrowth. (A) Immunoblot showing expression of GFP-tagged $M_{1} R$ protein in DRG neurons. $M_{1} R$ cDNA was cloned in PEGFP-C1 vector and used for transient transfection of DRG neurons using Amaxa Nucleofection reagent. Cells were harvested 24 hours after transfection, and proteins were separated by SDS-PACE, followed by immunoblotting using anti-GFP and anti-M, antibodies. (B) Bright-field (BF) and fluorescence images showing expression of GFP and GFP-M,R in neurons. Note extensive growth in GFP- vs. GFP-M $\mathrm{M}_{1}$-overexpressing neuron. (C) Fluorescent and immunostained images showing expression of GFP-tagged $\mathrm{M}_{1} \mathrm{R}$ in DRG neurons. Neurons were immunostained for $\beta$-tubulin III. Neurons with coexpression of GFP-M,R and $\beta$-tubulin III exhibited reduced neurite outgrowth compared with neurons expressing GFP alone. Scale bars: $100 \mu \mathrm{m}$. Colocalization of GFP (green) and $\beta$-tubulin III (red) indicated by yellow. (D) Neurons were transfected with GFP or GFP-M R plasmids and maintained in vitro for 48 hours and immunostained for $\beta$-tubulin III. Total neurite outgrowth is shown as mean + SEM of $n=51$ neurons; open circles indicate individual data points. ${ }^{* * *} P<0.0001$, Student's unpaired $t$ test. (E) Cultures overexpressing GFP-M, $R$ were treated with $100 \mathrm{nM}$ MT7 or $1 \mu \mathrm{M}$ pirenzepine for 48 hours. Total neurite outgrowth is shown as group median with $n=100$ neurons. ${ }^{* *} P<0.001 ;$ ${ }^{* * * *} P<0.0001$ vs. control by 1-way ANOVA with Dunnett's post-hoc test. Box and whisker plot where upper and lower limits of box indicate 75 th and 25 th percentiles, respectively. The middle lines show median, and error bars show maximum and minimum values. (F) WT (+/+) or $\mathrm{M}_{1} \mathrm{R}$ knockout ( $\left.M_{1} R-K O\right)$ mouse cultures were maintained for 48 hours in the presence of a low- (LD), medium- (MD), or high-dose (HD) neurotrophic factor cocktail. Total neurite outgrowth is shown as mean + SEM of $n=8$ replicate cultures. ${ }^{*} P<0.05 ;{ }^{*} P<0.01$, Student's $t$ test.

article; doi:10.1172/JCI88321DS1; and previously described in ref. 28) identified pirenzepine, a selective $M_{1} R$ antagonist (29), as able to induce a dose-dependent ( 3 to $100 \mathrm{nM}$ ) increase of total neurite outgrowth from neurons derived from normal rats (Figure 1, A and B). This effect was mimicked by $30 \mathrm{nM} \mathrm{VU0255035,} \mathrm{a}$ structurally dissimilar but also selective $M_{1} R$ antagonist (30) (Figure $1 \mathrm{C}$ ). Selective antagonists of the $\mathrm{M}_{2} \mathrm{R}$ (gallamine, $\left.1 \mu \mathrm{M}\right), \mathrm{M}_{3} \mathrm{R}$ (darafenacin, $1 \mu \mathrm{M}$ ) (31), or $\mathrm{M}_{4} \mathrm{R}$ (tropicamide, $1 \mu \mathrm{M}$ ) (32) had no effect on neurite outgrowth (Figure 1C). The muscarinic receptor agonist muscarine $(10 \mu \mathrm{M})$ significantly inhibited neurite outgrowth, by approximately $50 \%$ (Figure 1D). As ACh also activates a variety of nicotinic receptor subtypes in neurons, we determined whether blockade of this signaling pathway also modulated neurite outgrowth. The broad-spectrum nicotinic antagonists hexa- 
A

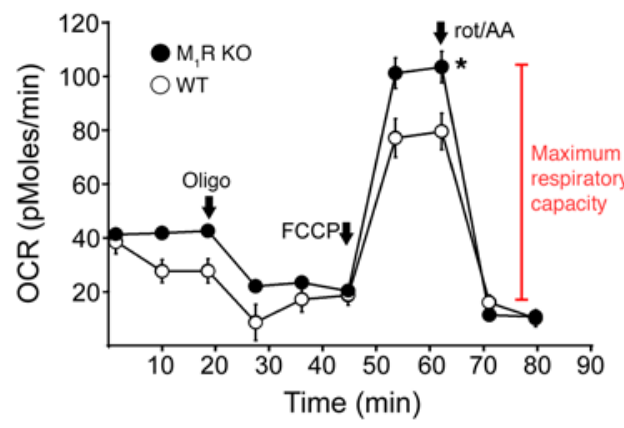

B
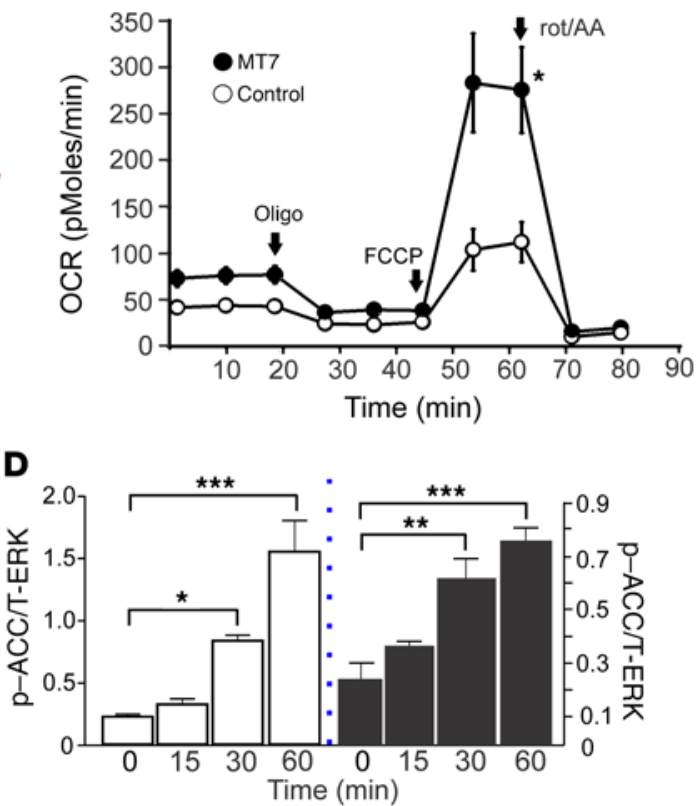

C

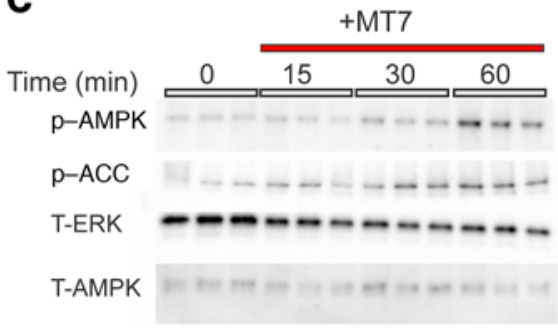

$\mathbf{F}$
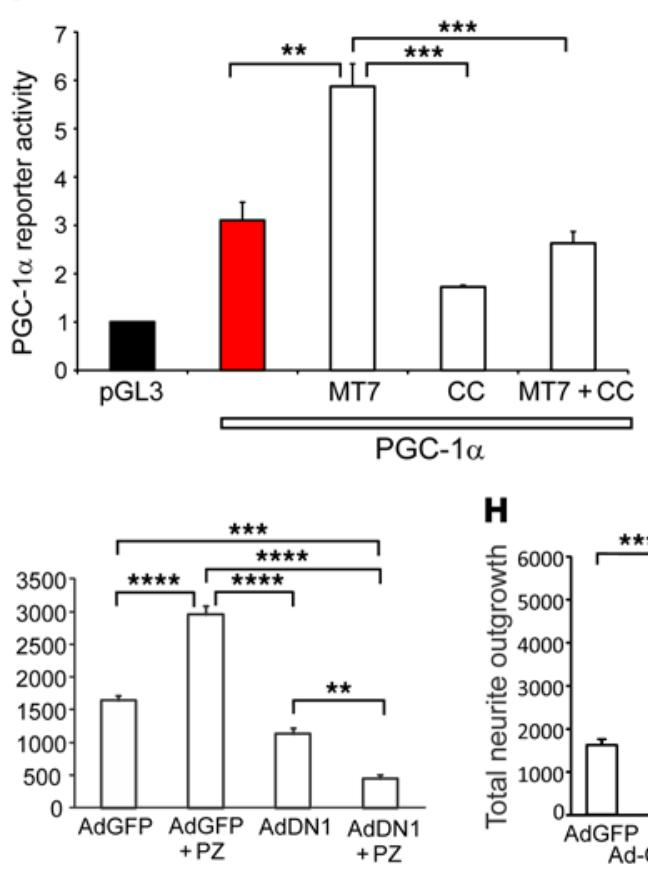

H

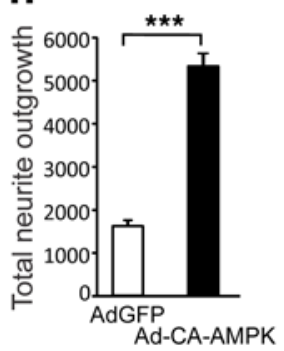

Figure 3. $M_{1} R$ blockade augmented mitochondrial function and elevated neurite outgrowth via AMPK/PGC-1a. (A) DRG cultures from adult $M_{1} R-K O$ mice and WT mice. OCR per 1,000 neurons. Oligo, oligomycin; rot/AA, rotenone plus antimycin A. Arrows indicate time added. (B) Neurons from STZ-induced diabetic mice were maintained overnight and exposed to $100 \mathrm{nM} \mathrm{MT7}$ or vehicle for 1 hour. (A and B) Data are shown as mean $\pm \mathrm{SEM}$ of $n=4-5$ replicate cultures. ${ }^{*} P<0.05$ vs. WT or untreated diabetic mice by unpaired Student's $t$ test. Neurons from diabetic rats were exposed to $100 \mathrm{nM} M T 7$ for various times. Blots for p-AMPK and p-ACC in C and $\mathbf{D}$ data normalized to total ERK (T-ERK). Data are shown as mean + SEM of $n=3$ replicate cultures. ${ }^{*} P<0.05$; ${ }^{* *} P<0.01$; ${ }^{* *} P<0.001$ vs. time 0 by 1-way ANOVA with Dunnett's post-hoc test. (E) Reporter assay for PGC-1 $\alpha$ in neurons from STZ-diabetic rats exposed to $10 \mu \mathrm{M}$ VU0255035 or $100 \mathrm{nM}$ MT7 for 1 hour. Data are shown as mean + SEM of $n=3$ replicate cultures. ${ }^{*} P<0.05$ vs. untreated cells (red bar) by 1 -way ANOVA with Dunnett's post-hoc test. Normalized to control plasmid, pGL3 (black bar). (F) Reporter activity for PGC-1 $\alpha$ in neurons from STZ-diabetic rats exposed to $100 \mathrm{nM} \mathrm{MT7}$ or $0.3 \mu \mathrm{M} \mathrm{CC}$ or in combination for 30 minutes. Untreated is shown as red bar. Data are shown as mean $+\mathrm{SEM}$ of $n=3$ replicate cultures. ${ }^{* *} P<0.01 ;{ }^{* *} P<0.001$, 1-way ANOVA with Tukey's post-hoc test. (G-H) Total neurite outgrowth of neurons from diabetic rats transduced with adenovirus carrying dominant negative mutants of $\alpha 1$ (DN1) or $\alpha 2$ (DN2) subunits of AMPK. (H) Constitutively active $\alpha 1$ subunit of AMPK (Ad-CA-AMPK) expressed. Data are shown as mean + SEM of $n=3$ replicate cultures. (C) ${ }^{* *} P<0.01$; ${ }^{* *} P<0.001 ;{ }^{* * *} P<0.0001$ by 1 -way ANOVA with Tukey's post-hoc test. $(\mathbf{H}){ }^{* * *} P<0.05$ by Student's unpaired $t$ test. 
A
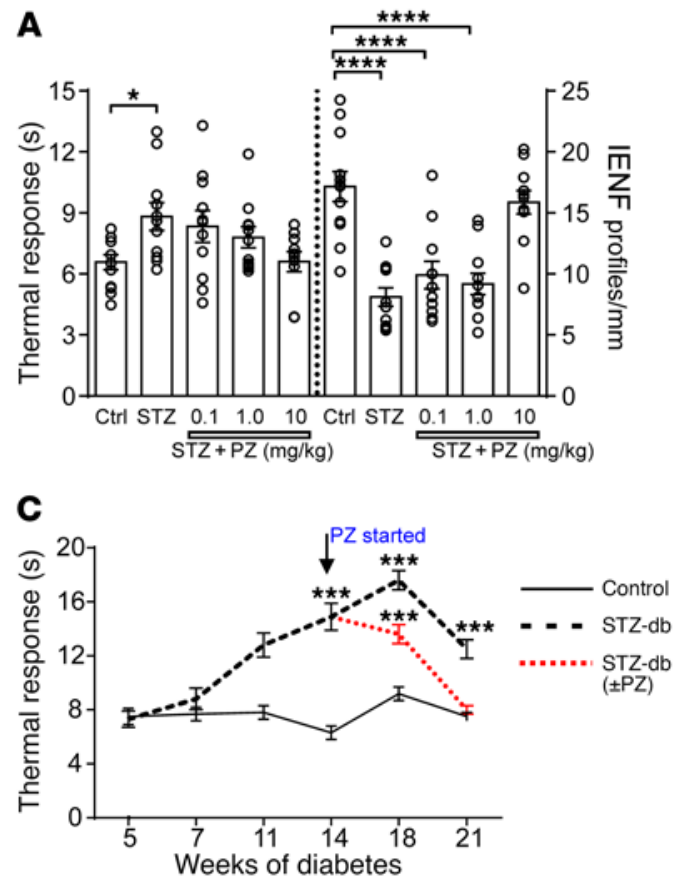

B

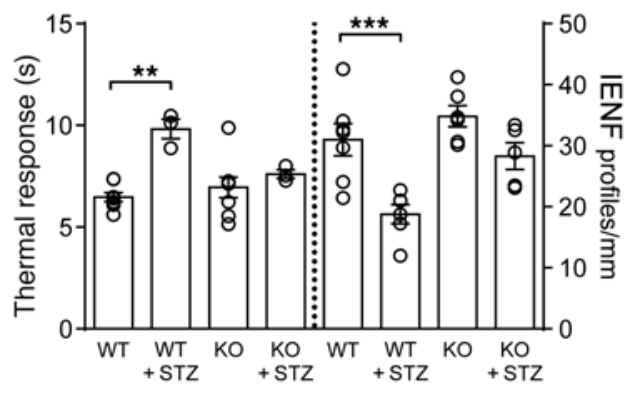

D

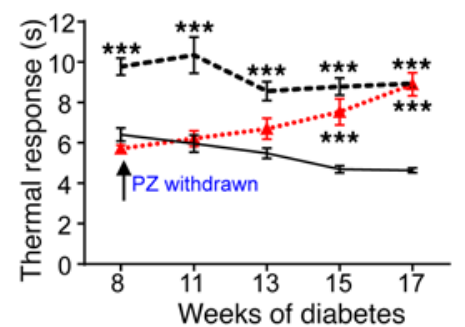

E

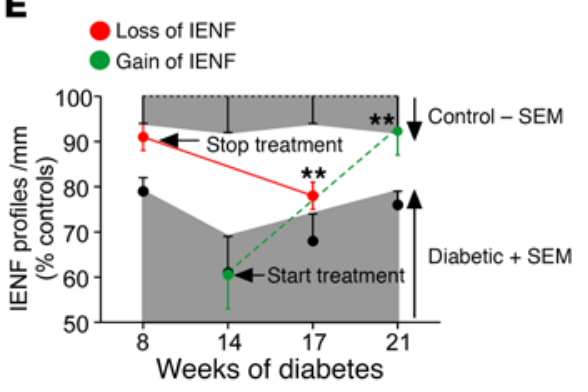

$\mathbf{F}$

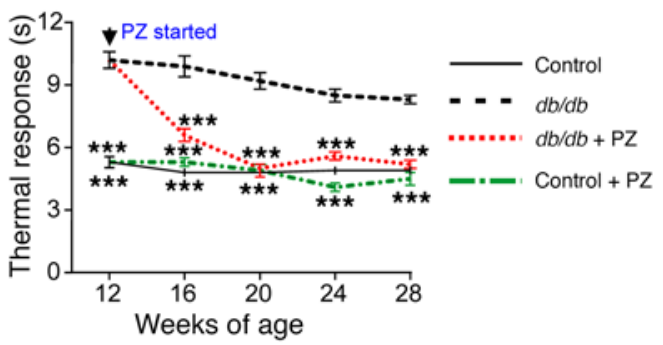

Figure 4. $M_{1} \mathbf{R}$ antagonism prevents and reverses diabetic sensory neuropathy. (A) Thermal response latency and paw skin IENF density in female C57BL/6 (Ctrl, control) and STZ-diabetic mice \pm pirenzepine (0.1-10 mg/kg/d s.c.) after 4 weeks of diabetes. Data are shown as mean \pm SEM of $n=11-12$. ${ }^{*} P<0.05 ;{ }^{* * *} P<0.0001$ vs. control by 1-way ANOVA with Dunnett's post-hoc test. (B) Thermal response latency and paw skin IENF density in WT and $\mathrm{M}_{1} \mathrm{R}-\mathrm{KO}$ mice after 6 weeks (thermal response) or 12 weeks (IENF) of STZ-induced diabetes. Data are shown as mean \pm SEM of $n=3-7$. ${ }^{* *} P<0.01$; ${ }^{* *} P<0.001$ vs. WT by 1 -way ANOVA with Dunnett's post-hoc test. (C) Thermal response latency in Swiss Webster, STZ-diabetic, and STZ-diabetic mice with pirenzepine ( $10 \mathrm{mg} / \mathrm{kg} /$ day s.c.) from 14 weeks. Data are shown as mean $\pm \mathrm{SEM}$ of $n=8-10 .{ }^{* *} P<0.001$ vs. control by repeated-measures 2 -way ANOVA and Dunnett's post-hoc test. (D) Thermal response latency in female C57BL/6 mice, STZ-diabetic mice, and STZ-diabetic mice with pirenzepine $\left(10 \mathrm{mg} / \mathrm{kg} / \mathrm{d}\right.$ s.c.) up to 8 weeks, when treatment was withdrawn. Data are shown as mean \pm SEM of $n=8-10 .{ }^{* *} P<0.001$ vs. control by repeatedmeasures 2-way ANOVA and Dunnett's post-hoc test. Groups as indicated by key in $\mathbf{C}$. (E) Paw IENF density in mice where thermal response latency shown in C (14 weeks and 21 weeks of diabetes) and $\mathbf{D}$ ( 8 weeks and 17 weeks of diabetes), normalized to IENF of control mice at same time. The mean - SEM of control mice at each time point defined lower limit of control group range, and mean + SEM of STZ-diabetic mice at each time point defined upper limit of diabetic group range. Data are shown as mean \pm SEM of $n=8-10$. ${ }^{* *} P<0.01$ vs. start or cessation of treatment in same cohort by unpaired $t$ test. (F) Paw thermal response latency in male C57BL/6 mice, $d b / d b$ mice, and C57BL/6 or $d b / d b$ mice with pirenzepine $(10 \mathrm{mg} / \mathrm{kg} / \mathrm{d} \mathrm{s.c.)} \mathrm{from} 12 \mathrm{weeks}$ onwards. Data are shown as mean \pm SEM of $n=9-10$. ${ }^{* *} P<0.001 \mathrm{vs}$. $d b / d b$ by repeated-measures 2-way ANOVA and Dunnett's post-hoc test.

methonium $(20 \mu \mathrm{M})$ and mecamylamine $(50 \mu \mathrm{M})$ had no effect on neurite outgrowth (Figure 1D). Pirenzepine and VU0255035 are selective $\mathrm{M}_{1} \mathrm{R}$ antagonists, whereas the only specific antagonist of the $\mathrm{M}_{1} \mathrm{R}$ is muscarinic toxin 7 (MT7) (33). Concentrations of MT7 as low as $10 \mathrm{nM}$ significantly augmented neurite outgrowth (Figure 1E). The capacity of adult sensory neurons to support cholinergic signaling was confirmed using fluo-4 loading and fluorescence video microscopy. Application of $50 \mu \mathrm{M}$ muscarine caused an acute and transient increase of intracellular $\mathrm{Ca}^{2+}$ levels that was inhibited by prior exposure ( 2 minutes) to $1.0 \mu \mathrm{M}$ pirenzepine or $0.1 \mu \mathrm{M}$ atropine, a nonspecific antimuscarinic (Figure 1, F-H).
Overexpression of $M_{1} R$ inhibits neurite outgrowth. We constructed a plasmid that overexpressed a full-length rat GFP-M ${ }_{1} R$ fusion protein (Figure 2A). Adult sensory neurons transfected with this plasmid exhibited low levels of neurite outgrowth compared with neurons transfected with GFP alone (Figure 2, B-D). The brightfield images in Figure 2B show that GFP-expressing neurons exhibited extensive neurite outgrowth and that this was stunted by overexpression of GFP-M $\mathrm{M}_{1} \mathrm{R}$. Immunocytochemistry confirmed that neurite outgrowth was significantly suppressed in neurons overexpressing GFP-M $\mathrm{M}_{1} \mathrm{R}$ (Figure 2, C and D). Diminished neurite outgrowth by neurons that overexpressed GFP-M $\mathrm{M}_{1} \mathrm{R}$ was par- 
A

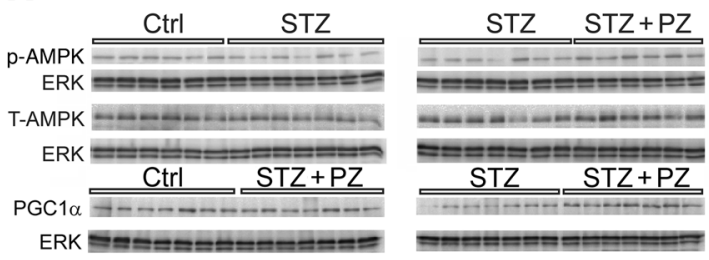

B
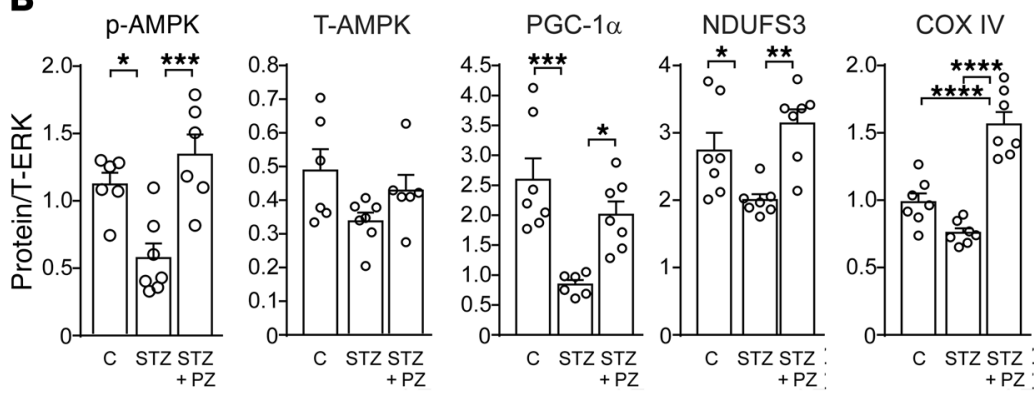

C
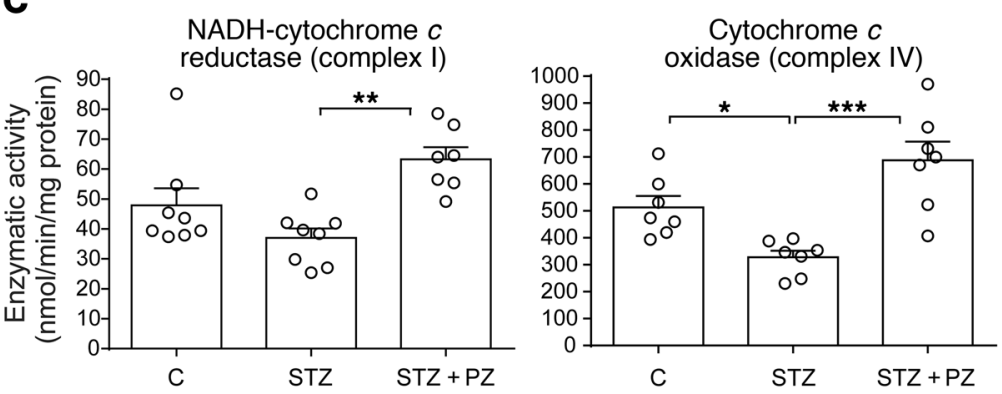

Figure 5. Pirenzepine augments AMPK/PGC-1 $\alpha$ pathway gene expression and mitochondrial activity in STZ-diabetic mice. (A and B) DRG homogenates from animals reported in Figure 4, C and $E$ (21-week time point), underwent Western blotting and were probed for p-AMPK (on Thr-172), T-AMPK, PGC-1 $\alpha$, NDUFS3 (complex I), and COX IV (complex IV). ERK was probed as a loading control. Data are calculated relative to T-ERK and expressed as mean \pm SEM of $n=5$-6/group. ${ }^{*} P<0.05$; ${ }^{* *} P<0.01$; ${ }^{* *} P<0.001$; ${ }^{* * *} P<0.0001$, 1-way ANOVA with Tukey's post-hoc test. (C) DRG homogenates from the same study were analyzed for respiratory chain complex activities. Data are shown as mean \pm SEM of $n=8$ /group. ${ }^{*} P<0.05 ;{ }^{* *} P<0.01 ;{ }^{* * *} P<0.001,1$-way ANOVA with Tukey's post-hoc test.

tially rescued by treatment with MT7 $(100 \mathrm{nM})$ or pirenzepine $(1 \mu \mathrm{M}$; Figure $2 \mathrm{E})$. To further establish the specific role of the $\mathrm{M}_{1} \mathrm{R}$, we next cultured sensory neurons from adult $\mathrm{M}_{1} \mathrm{R}$-deficient mice ( $\mathrm{M}_{1} \mathrm{R}-\mathrm{KO}$ mice), having confirmed neuronal $\mathrm{M}_{1} \mathrm{R}$ expression in WT mice and lack thereof in $\mathrm{M}_{1} \mathrm{R}-\mathrm{KO}$ mice (Supplemental Figure 3A). Neurons from adult $\mathrm{M}_{1} \mathrm{R}-\mathrm{KO}$ mice showed enhanced neurite outgrowth when maintained under a low- or medium-dose concentration of a cocktail of neurotrophic growth factors in the culture medium, compared with those from WT mice (Figure 2F). In the presence of high-dose concentrations of growth factors, the inhibitory effect of the $M_{1} R$ pathway was not observed.

As ACh was not a component of the culture media, we hypothesized that, under cell culture conditions, the $\mathrm{M}_{1} \mathrm{R}$-mediated modulation of neurite outgrowth involved neuron-derived ACh. We confirmed that sensory neurons expressed the peripheral form of ChAT (25) (Supplemental Figure 3B) and ACh was detected in the culture medium from neurons grown at the same density as in all other experiments $(16.52 \pm 1.42 \mathrm{nmol} / \mathrm{ml})$. Cultured neurons exhibited immunostaining for ChAT in perikarya, axons, and growth cones when using an antibody with selectivity for peripheral ChAT (Supplemental Figure 3, C-E). We therefore propose that the cholinergic phenotype of isolated adult sensory neurons places a tonic constraint on neurite outgrowth via a mechanism involving sensory neuron-derived $\mathrm{ACh}$ and the $\mathrm{M}_{1} \mathrm{R}$.

Muscarinic receptor blockade enhances mitochondrial function. Neuronal growth cones require optimal mitochondrial function to produce ATP for axon growth/plasticity, and sensory axons exhibit a high density of condensed organelles reflective of high ATP demand $(5,8,34)$. Given the constraint on neurite outgrowth imposed by ACh, we investigated whether manipulation of cholinergic systems operating in peripheral sensory neurons altered mitochondrial regulatory pathways. We first measured the oxygen consumption rate (OCR) of isolated adult sensory neurons to determine whether $M_{1} R$ inhibition directly affects neuronal respiration. Neurons derived from $\mathrm{M}_{1} \mathrm{R}-\mathrm{KO}$ mice exhibited enhanced spare respiratory capacity compared with those from WT mice without any concurrent change in basal respiration, coupling efficiency, or respiratory control ratio (Figure 3A and Supplemental Figure 4A). This suggests that ongoing cholinergic signaling via the $\mathrm{M}_{1} \mathrm{R}$ constrains mitochondrial maximal respiratory capacity, which will restrict mitochondrial ATP generation under conditions of high demand.

Neurons derived from STZ-induced diabetic rodents exhibited oxidative stress, reduced spare respiratory capacity, and when dissociated and placed in culture, impaired neurite outgrowth $(4,11$, 35). Spare respiratory capacity was increased in these neurons by the $M_{1} R$ antagonists MT7 $(100 \mathrm{nM}$, in STZ-mouse DRG culture) (Figure 3B and Supplemental Figure 4B), VU0255035 (10 $\mu \mathrm{M}$, in STZ-rat DRG culture), or pirenzepine ( $1 \mu \mathrm{M}$, in STZ-mouse DRG culture) (Supplemental Figure 4D). Note that in all studies of neurons derived from STZ-induced diabetic rodents, the basal rate of respiration was not significantly different from that of age-matched controls. This confirms previous work from our laboratory and others $(11,36-38)$. Neurons derived from STZ-diabetic mice also exhibited enhanced neurite outgrowth when exposed to pirenzepine $(1 \mu \mathrm{M})$ or MT7 (100 nM) (Supplemental Figure $4 \mathrm{C})$, further illustrating the potential of antagonizing endogenous muscarinic receptor activity to overcome a disease phenotype.

$M_{1} R$-selective antagonists activate the AMPK pathway to drive neurite outgrowth. A key pathway that senses cellular energy demands and modulates mitochondrial function is the AMPK and PGC- $1 \alpha$ signaling axis (39). Exposure of sensory neurons derived from STZ-induced diabetic rats to $100 \mathrm{nM}$ MT7 or $10 \mu \mathrm{M}$ VU0255035 enhanced activation (phosphorylation) of AMPK and its endogenous substrate, acetyl-CoA carboxylase (ACC) (Figure 3, C and D, and Supplemental Figure 4E). MT7, VU0255035, and pirenzepine also augmented luciferase reporter activity for PGC-1 $\alpha$, a downstream target of AMPK, when added to neurons derived from STZ-diabetic rats (Figure $3 \mathrm{E}$ and 
A

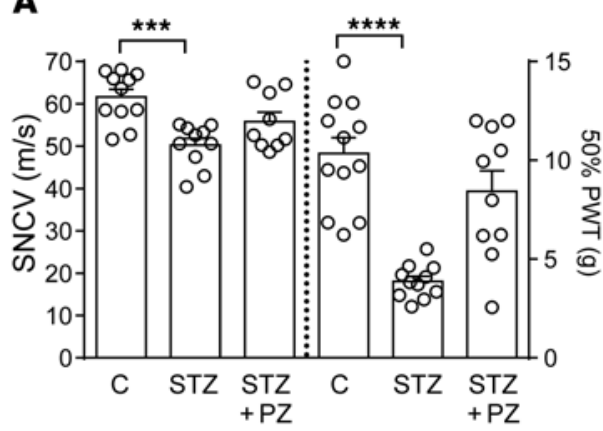

B

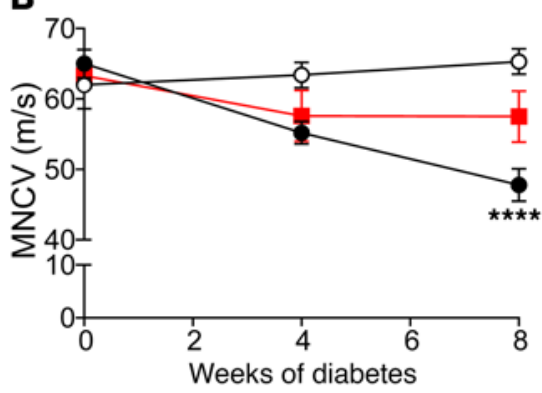

C

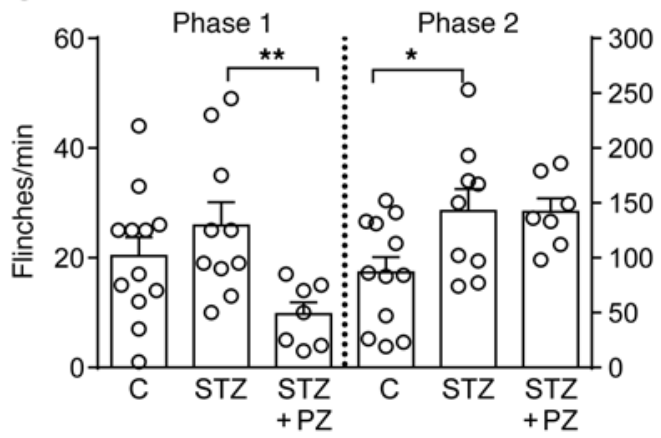

Figure 6. $M_{1} R$ antagonism prevents nerve-conduction deficits and tactile allodynia in diabetic neuropathy. (A) SNCV (left panel) and 50\% paw withdrawal threshold (PWT, right panel) to von Frey filaments (right panel) in control female Sprague-Dawley rats (C), STZ-diabetic rats (STZ), and diabetic rats treated with pirenzepine at $10 \mathrm{mg} / \mathrm{kg} / \mathrm{d}$ s.c. for the last given 24 hours before assay (STZ+PZ) after 8 weeks of diabetes. Data are shown as mean \pm SEM of $n=8-12$ /group. ${ }^{* *} P<0.001$; ${ }^{* * * *} P<0.0001$ vs. control by 1-way ANOVA with Dunnett's post-hoc test. (B) Time course of sciatic MNCV in male Wistar rats (open circles), STZ-diabetic rats (black circles), and STZ-diabetic rats treated with pirenzepine $(5 \mathrm{mg} / \mathrm{kg} / \mathrm{d}$ s.c.) for 8 weeks of diabetes (red squares). Data are shown as mean \pm SEM of $n=5$-8/group. ${ }^{* * *} P<0.0001$ vs. control by repeated-measures 2-way ANOVA with Dunnett's post-hoc test. (C) Paw flinching in response to subdermal injection of $50 \mu \mathrm{l} 0.5 \%$ formalin to the dorsal hind paw of female Sprague-Dawley rats (C), diabetic rats (STZ), and diabetic rats treated with pirenzepine ( $10 \mathrm{mg} / \mathrm{kg} /$ day s.c.) daily from onset of diabetes for 8 weeks and last given 24 hours before assay (STZ+PZ). Phase 1 represents the sum of flinches during minutes $1-2,6-7$, and $11-12$, and phase 2 represents the sum of flinches during minutes 16-17, 21-22, 26-27, 31-32, 36-37, 41-42, 46-47, 51-52, 56-57, and 61-62 after paw formalin injection. Data are shown as mean + SEM of $n=8-11 /$ group. ${ }^{*} P<0.05$; ${ }^{* *} P<0.01$ vs. STZ by 1-way ANOVA with Dunnett's post-hoc test.
Supplemental Figure 4F). MT7 enhancement of PGC-1 $\alpha$ was blocked by compound C $(0.3 \mu \mathrm{M})$, a well-characterized pharmacological inhibitor of AMPK (Figure 3F). The mechanistic association between $M_{1} R$ regulation of AMPK activation and neurite outgrowth was confirmed using sensory neurons derived from STZ-induced diabetic rats transduced with adenovirus carrying dominant negative mutants of AMPK $\alpha 1$ and AMPK $\alpha 2$ subunits. Neurons overexpressing mutant AMPK did not show enhanced neurite outgrowth in response to $1 \mu \mathrm{M}$ pirenzepine (Figure $3 \mathrm{G}$ and Supplemental Figure 4G), whereas overexpression of a constitutively active mutant of AMPK augmented neurite outgrowth (Figure $3 \mathrm{H}$ ). Thus, ongoing activity of $\mathrm{M}_{1} \mathrm{R}$ and subsequent dampening of the AMPK/PGC- $1 \alpha$ signaling axis restricted the capacity of sensory neurons to respond to increased energy demands such as those required to sustain neurite outgrowth.

$M_{1} R$ antagonism prevents and reverses indices of diabetic neuropathy in mice. Mitochondrial dysfunction is linked to the onset of diabetic peripheral neuropathy (2-4). We therefore tested the therapeutic potential of antagonizing muscarinic receptor-mediated suppression of mitochondrial function in diabetic mice, a model that reflects human diabetic neuropathy by developing loss of terminal regions of small sensory fibers and loss of sensorimotor function (40). We focused on pirenzepine as the test agent due to its well-characterized pharmacokinetics/dynamics, limited penetration of the blood-brain barrier, and history of safe clinical use for other indications (41). Pirenzepine did not alter disease severity, as body weight, plasma glucose, and HbA1c were unchanged (Supplemental Table 1). Analysis of expression of the $\mathrm{M}_{1} \mathrm{R}$ in the DRG of C57BL/6 mice with STZ-induced diabetes revealed no significant change in mRNA expression (Supplemental Figure 5). Adult C57BL/6 mice with STZ-induced type 1 diabetes developed loss of paw IENF (illustrated in Supplemental Figure 6A) with concurrent thermal hypoalgesia, and both disorders were prevented by pirenzepine in a dose-dependent fashion (Figure 4A). Mice lacking the $\mathrm{M}_{1} \mathrm{R}$ had normal response times to paw heat stimulation and normal paw-skin IENF density when compared with WT mice (Figure 4B). Induction of diabetes in WT mice caused paw thermal hypoalgesia and depletion of IENF, whereas induction of diabetes in mice lacking the $\mathrm{M}_{1} \mathrm{R}$ was without effect on these parameters (Figure 4B). Importantly for potential clinical translation, the therapeutic capacity of pirenzepine extended to reversal of established neuropathy in mouse models of type 1 (STZ) and type $2(d b / d b)$ diabetes (Figure 4, C, E, and F). Moreover, efficacy persisted for 5 to 9 weeks after cessation of treatment (Figure 4, D and E). The efficacy of pirenzepine was replicated by VU0255035, which also corrected loss of thermal sensation and IENF depletion without affecting disease severity in a mouse model of type 1 diabetes (Supplemental Figure 6B).

Pirenzepine-dependent recovery from diabetic neuropathy was associated with correction of mitochondrial dysfunction. Concurrent protection of mitochondria was confirmed by assays performed on sensory ganglia derived from diabetic rodents. Diabetesinduced defects in AMPK/PGC-1 $\alpha$, mitochondrial complex protein expression, and OCR were absent in pirenzepine-treated models of type 1 and type 2 diabetes (Figure 5, A and B, and Supplemental Figure 6, C-E). Furthermore, pirenzepine corrected the depression of respiratory chain complex I and IV activities in DRG obtained from 
A

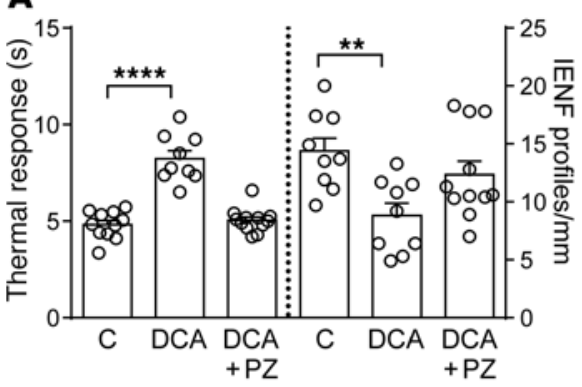

C

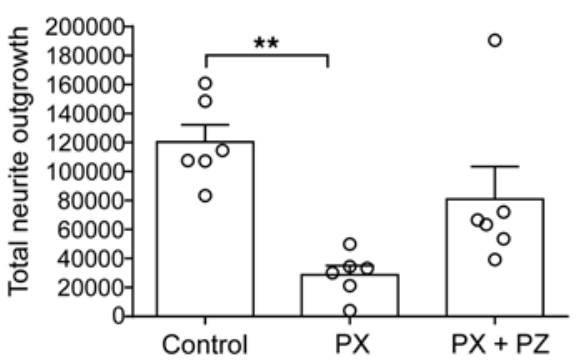

B

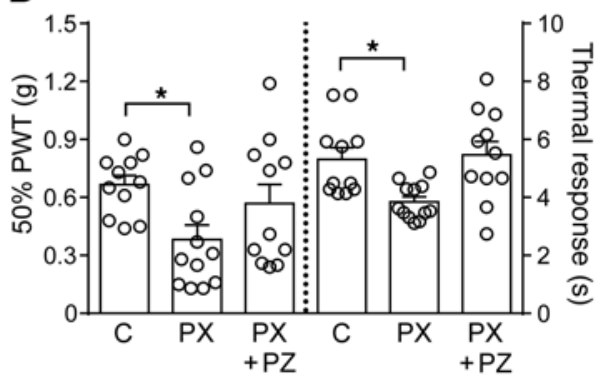

D

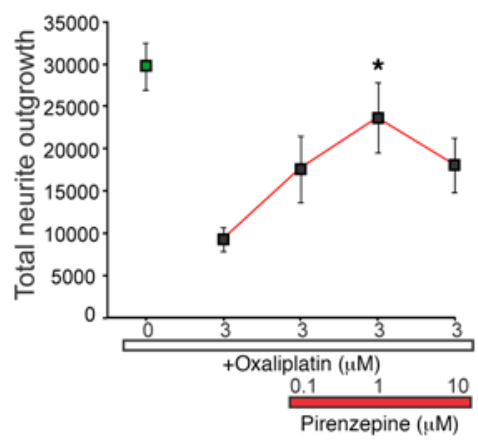

Figure 7. M,R antagonists are neuroprotective in models of CIPN. (A) Paw thermal response latency (left panel) and IENF profiles (right panel) in female Swiss Webster mice (C), DCA-exposed mice (DCA), and DCA-exposed mice treated with pirenzepine $(10 \mathrm{mg} / \mathrm{kg} / \mathrm{d}$ s.c. last given 24 hours before assay) for 8 weeks during DCA exposure (DCA+PZ). (B) Paw withdrawal threshold (left panel) and thermal response latency (right panel) in female Swiss Webster mice (C), paclitaxel-exposed mice (PX), and paclitaxel-exposed mice treated with pirenzepine $(10 \mathrm{mg} / \mathrm{kg} / \mathrm{d}$ s.c. for 4 weeks following the last paclitaxel exposure and last given 24 hours before assay; PX+PZ). Data in A-B are shown as group mean + SEM of $n=9-12$ /group. ${ }^{*} P<0.05$; ${ }^{* *} P<0.01 ;{ }^{* * *} P<0.0001$ vs. control by 1-way ANOVA with Dunnett's post-hoc test. Neurite outgrowth in adult sensory neuron cultures exposed to $(\mathbf{C})$ paclitaxel $(0.3 \mu \mathrm{M})$ or $(\mathbf{D})$ oxaliplatin $(3 \mu \mathrm{M})$ for 1 day in the absence/presence of $1 \mu \mathrm{M}$ (C) or 0.1-10 $\mu \mathrm{M}$ (D) pirenzepine. Data are shown as mean \pm SEM of $n=5-8$ replicates/group. (C) ${ }^{* *} P<0.01,1$-way ANOVA with Tukey's post-hoc test. (D) ${ }^{*} P<0.05$ vs. oxaliplatin alone by 1-way ANOVA with Dunnett's post-hoc test.

the same diabetic animals (Figure 5C). These data establish the therapeutic potential of $\mathrm{M}_{1} \mathrm{R}$ antagonism against functional and structural indices of small fiber sensory neuropathy in diverse models of type 1 and type 2 diabetes in conjunction with protection of AMPK and mitochondrial activity in the sensory ganglia of such animals.

$M_{1} R$ antagonism prevents diabetic neuropathy in other models. The ability of $\mathrm{M}_{1} \mathrm{R}$ antagonism to prevent loss of thermal sensation and IENF in mice extended to other indices of neuropathy measured in other species. Reduced large-fiber sensory nerve-conduction velocity (NCV) and increased sensitivity to light touch (Figure 6A) in female STZ-diabetic rats and progressive large-fiber motor nerve-conduction velocity (MNCV) slowing in male STZ-diabetic rats (Figure 6B) were prevented by pirenzepine without affecting disease severity (Supplemental Table 2). These findings demonstrate that efficacy of treatment with this $\mathrm{M}_{1} \mathrm{R}$ antagonist was not species, fiber type, or sex specific. Pirenzepine did not act as an acute antinociceptive agent or general sedative, as a single dose to otherwise untreated STZdiabetic rats did not affect paw tactile responses (Supplemental Figure 7A) or motor function (Supplemental Figure 7B). However, pirenzepine treatment suppressed primary afferent-driven phase 1 activity during the paw formalin test in STZ-diabetic rats without altering the increased paw flinching during phase 2 (Figure 6C). As pirenzepine has poor CNS penetration (42), a peripheral mode of action against phase 1 activity in the formalin test may be suspected.

$M_{1} R$ antagonists are neuroprotective in models of chemotherapy- and HIVinduced peripheral neuropathy. The neuroprotective effects of pirenzepine were not restricted to diabetic neuropathy. Dichloracetic acid (DCA) is a compound under investigation as a cancer treatment that causes dose-dependent peripheral neuropathy (43). The paw thermal hypoalgesia and loss of IENF that are indicative of degenerative neuropathy in mice following chronic exposure to DCA were prevented by pirenzepine (Figure 7A). Paw tactile allodynia and thermal hyperalgesia, indicative of painful neuropathy in mice exposed to the chemotherapeutic agent paclitaxel, were also prevented by treatment with pirenzepine (Figure 7B). To confirm that pirenzepine can have direct protective effects on peripheral neurons undergoing stress from exposure to chemotherapeutic agents, we isolated neurons from the DRG of normal rats and measured subsequent neurite outgrowth during exposure to the chemotherapeutic agent paclitaxel $(0.3 \mu \mathrm{M})$ or oxaliplatin $(3.0 \mu \mathrm{M})$. Reduced total neurite outgrowth induced by these agents was prevented by exposure to 1 to $10 \mu \mathrm{M}$ pirenzepine (Figure 7, C and D). To extend our investigations to a model of HIV-associated neuropathy, we exposed adult DRG neurons in culture to the HIV envelope protein gp120, which causes direct axonal damage (44). The reduced neurite outgrowth from gp120-exposed DRG neurons was prevented by $1 \mu \mathrm{M}$ pirenzepine (Figure $8 \mathrm{~A}$ ). Delivery of gp120 to the eye of normal mice daily for 5 weeks induced reduced nerve density in the corneal subbasal nerve plexus, as detected using noninvasive corneal confocal microscopy (Figure 8, B-E). Loss of corneal nerves was both prevented and reversed by concurrent topical application of the specific $\mathrm{M}_{1} \mathrm{R}$ antagonist MT7 (Figure 8F).

\section{Discussion}

We have discovered that adult peripheral sensory neurons maintained in vitro exhibit ongoing cholinergic constraint of mitochondrial function and neurite outgrowth. The signal transduction pathway linking $\mathrm{M}_{1} \mathrm{R}$ receptor activity to modulation of the AMPK/PGC-1 $\alpha$ axis and mitochondrial function in neurons can be antagonized, and blocking this pathway may contribute to our observations of neuroprotection and recovery from injury promoted by $\mathrm{M}_{1} \mathrm{R}$ antagonists in models of metabolic-, chemical-, and HIV-related peripheral neuropathy. 
A
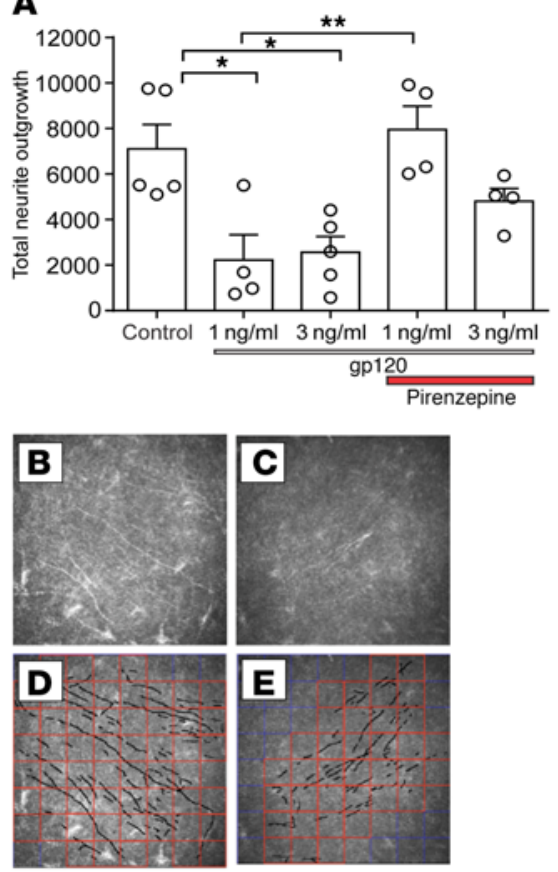

$\mathbf{F}$

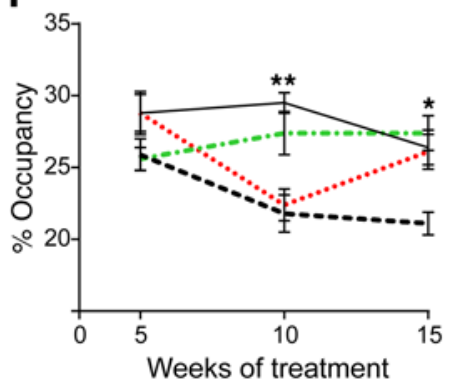

Figure 8. $M_{1} R$ antagonists are neuroprotective in models of peripheral neuropathy induced by the HIV envelope protein gp120. (A) Neurite outgrowth in adult sensory neuron cultures exposed to gp120 $(1-3 \mathrm{ng} / \mathrm{ml})$ $\pm 1 \mu \mathrm{M}$ pirenzepine for 24 hours. Data are shown as mean + SEM of $n=5-8$ replicate cultures. ${ }^{*} P<0.05$; ${ }^{* *} P<0.01,1$-way ANOVA with Tukey's post-hoc test. (B-C) Unprocessed and (D-E) processed images corneal nerves of the subbasal plexus. Dimensions $=400 \times 400 \mu \mathrm{m}$, resolution $=384 \times 384$ pixels (B) Corneal nerves from a control Swiss Webster mouse. (C) Corneal nerves from a Swiss Webster mouse that received daily eye drops of gp120 for 10 weeks. ( $\mathbf{D}$ and $\mathbf{E}$ ) Same images overlaid with tracings of the corneal nerve and an $8 \times 8$ counting grid. Grid squares bounded by red lines represent those that contain 1 or more corneal nerves. Panel $\mathbf{D}$ shows $56 / 64$ sectors that contain nerve (occupancy $=87.5 \%$ ), and panel $\mathbf{E}$ shows $36 / 64$ sectors containing nerve (occupancy $=56.3 \%$ ). (F) Time course of subbasal plexus nerve density (as percentage of occupancy) in adult female Swiss Webster mice that received daily eye drops of vehicle (solid black line), gp120 (dashed black line), or both gp120 and MT7, where MT7 treatment was initiated either on the same day as gp120 (MT7 prevention, dot/dash green line) or 5 weeks after onset of gp120 treatment (MT7 reversal, dotted red line). Values are shown as mean \pm SEM of $n=10$. ${ }^{*} P<0.05$ for gp120 untreated vs. other groups; ${ }^{* *} P<0.01$ for gp120 untreated vs. MT7 prevention and vehicle by repeated-measures 2-way ANOVA and Dunnett's post-hoc test.

There are 5 distinct subtypes of muscarinic receptor $\left(\mathrm{M}_{1-5} \mathrm{R}\right)$ that are divided into 2 classes according to their $G$ proteincoupling preference (45). The $\mathrm{M}_{1}, \mathrm{M}_{3}$, and $\mathrm{M}_{5}$ subtypes couple to the $\mathrm{Gq} / \mathrm{G} 11 \mathrm{G}$ proteins, whereas the $\mathrm{M}_{2}$ and $\mathrm{M}_{4}$ subtypes link to
Gi/Go G proteins (45). While we cannot entirely exclude a contribution by other subtypes of this class when interpreting data using selective $M_{1} R$ antagonists, our data using $M_{1} R$-deficient mice, overexpression of GFP- $\mathrm{M}_{1} \mathrm{R}$, and the $\mathrm{M}_{1} \mathrm{R}$-specific antagonist MT7 indicate that this receptor subtype mediates cholinergic constraint of the AMPK/PGC-1 $\alpha$ axis, mitochondrial function, and neurite outgrowth. A role for endogenous $\mathrm{ACh}$ in regulating this pathway is supported by our measurement of secreted ACh detected in the culture medium, approximately $16 \mathrm{nmoles} / \mathrm{ml}$ $(16 \mu \mathrm{M})$, which far exceeds estimations of the ACh $K_{\mathrm{D}}$ of 0.2-0.4 $\mathrm{nM}$ for the $\mathrm{M}_{1} \mathrm{R}$ taken from studies with rat brain neurons (46, 47). These data also correspond well with extracellular levels of $\mathrm{ACh}$ in the range of 0.1 to $0.6 \mathrm{nM}$ detected using microdialysis in human and rat skin $(48,49)$. Thus, it is feasible that endogenously released ACh could act on $\mathrm{M}_{1} \mathrm{R}$ at nerve endings in the skin. In vitro work in the current study (Supplemental Figure 3, C-E) and in vivo studies in adult rat utilizing immunohistochemistry for the peripheral form of ChAT reveal that the protein is present in the cell body, axon, and nerve endings in the skin $(25,48)$. Furthermore, compartmented cultures using Campenot chambers of embryonic chick sensory neurons demonstrated secretion of ACh within the cell body compartment and also within the distal axonal compartment (49), emphasizing that ACh could be derived from sites along the whole sensory neuron axis.

The best-characterized role of $\mathrm{M}_{1} \mathrm{R}$ in the PNS is in sympathetic neurons, where it mediates the $M$ current (50). Acute ACh activation of $M_{1} R$ stimulates phospholipase $C \beta$ (PLC $\beta$ ) and triggers generation of inositol triphosphate, which induces endoplasmic reticulum $\mathrm{Ca}^{2+}$ release. Downstream $\mathrm{Ca}^{2+}$-dependent pathways drive closing of $\mathrm{K}_{\mathrm{v}} 7$ channels, and the outcome is an enhanced propensity for depolarization of the plasma membrane. Sensory neurons also express $\mathrm{K}_{\mathrm{v}} 7$ channels and exhibit the $\mathrm{M}$ current, but an initiating role of $M_{1} R$ in this pathway has not been confirmed (51). Upon axotomy, sensory neurons exhibit spontaneous electrical activity that consumes extensive ATP. Given our findings that $\mathrm{M}_{1} \mathrm{R}$ antagonism of axotomized adult sensory neurons in culture enhances neurite outgrowth, we speculate that blockade of the $\mathrm{M}$ current would reduce likelihood of depolarization, thus preserving ATP to support actin-treadmilling in the growth cone and enhancing axon outgrowth (5).

Sensory neuron culture data presented in Supplemental Figure 8 indicate that the antimuscarinic drug-driven activation of AMPK is mediated by $\mathrm{Ca}^{2+} /$ calmodulin-dependent protein kinase kinase $\beta$ (CaMKK $\beta)$, a well-characterized upstream kinase that phosphorylates AMPK in an AMP-independent manner (52). In cultured sensory neurons, lipid nanoparticle-mediated siRNA knockdown of CaMKK $\beta$ caused reduced phosphorylation of AMPK (Supplemental Figure $8 \mathrm{C}$ ) and a shift in isoelectric focusing to more positively charged, presumably less phosphorylated, AMPK isoforms (Supplemental Figure 8D). In nonneuronal transformed cells coexpressing Halo-CaMKK $\beta$ and $\mathrm{M}_{1} \mathrm{R}$ or Halo-AMPK $\alpha 2$ and $\mathrm{M}_{1} \mathrm{R}$, subsequent treatment with pirenzepine altered the charged state of CaMKK $\beta$ isoforms (Supplemental Figure 8E) and phosphorylation state of AMPK $\alpha 2$ isoforms (Supplemental Figure 8F), indicative of direct modulation via $\mathrm{M}_{1} \mathrm{R}$ (no effect was seen in the absence of $M_{1} R$ coexpression). Finally, in cultured sensory neurons, the MT7-induced phosphorylation of AMPK was blocked by the 
CaMKK inhibitor STO-609 (Supplemental Figure 8, G and H). The in vitro activation of AMPK in response to MT7 or VU0255035 developed slowly over 60 minutes (Figure 3, C and D, and Supplemental Figure 4E). Fluo-4 live imaging indicated that this activation of AMPK was associated with a rise of intracellular $\mathrm{Ca}^{2+}$ concentration in neurites over a 37.5-minute time period (Supplemental Figure 9). This observation seems counterintuitive, since, as shown in Figure 1, $\mathrm{F}-\mathrm{H}$, pirenzepine blocks the acute $\mathrm{Ca}^{2+}$ transient following muscarine treatment. However, this longer-term effect of $M_{1} R$ blockade, of as-yet-unknown genesis, that is driving elevation of intracellular $\mathrm{Ca}^{2+}$ concentration in axons could mediate activation of CaMKK $\beta$ and subsequently AMPK. AMPK activity maintains optimal mitochondrial function under high ATP demand, and this pathway is critical for axonal plasticity and growth-cone motility (5, 14-16). For example, the specific complex I inhibitor rotenone lowered intraneuritic ATP concentration and diminished neurite outgrowth in mouse adult sensory neurons (53) and embryonic rat neurons (54). Rotenone similarly blocked neurite outgrowth in adult sensory neurons, without concomitant cell death (P. Fernyhough, unpublished observations). In vivo, axotomy of adult sensory neurons causes mitochondrial depolarization and ATP depletion, and subsequent genetically mediated enhancement of mitochondrial trafficking elevates rates of nerve regeneration in response to a sciatic nerve crush (55). The pathogenic mechanisms that depress AMPK activity in peripheral neuropathies caused by diabetes (4) and paclitaxel (P. Fernyhough, unpublished observations) remain unclear. In nonneuronal cells from animal and human tissues, high extracellular glucose concentration drives down AMPK activity via nutrient stress (13). This inhibition of AMPK activity, and subsequently mitochondrial respiration, is mediated by a fall in the $\mathrm{AMP} / \mathrm{ATP}$ ratio, so that high intracellular glucose concentration funnels through glycolysis to generate ATP and obviates a requirement for extensive mitochondrial-dependent ATP production (56). An attractive feature of the $\mathrm{M}_{1} \mathrm{R}$-mediated activation of AMPK is that it likely occurs through an AMP-independent pathway, such as CaMKK $\beta$. Alternatively, it is possible that AMPK activation in response to $M_{1} R$ blockade is a consequence of neurite outgrowthdriven diminishment of local ATP supplies and a subsequent rise in the AMP/ATP ratio. Nevertheless, we have identified a therapeutic approach that may release mitochondrial respiration and neuronal plasticity from tonic cholinergic constraint and offers an alternative approach to neuroprotection and regeneration following acute stress or ongoing metabolic injury.

Antimuscarinic drugs were effective in several aspects of peripheral neuropathy. The ability of pirenzepine to reverse loss of IENF profiles in type 1 diabetes is the first experimental evidence, to our knowledge, showing reversal of this clinically significant end point. Previous studies have focused on prevention of IENF loss, for example, when studying protective effects of neurotrophin treatment in STZ-induced diabetic mice $(57,58) . \mathrm{M}_{1} \mathrm{R}-\mathrm{KO}$ mice were also protected from diabetic neuropathy, revealing a primary role for $M_{1} R$ in driving neuroprotection (Figure $4 \mathrm{~B}$ ). However, these findings require cautious interpretation. We found no evidence for diabetes altering the endogenous muscarinic receptor signaling pathway. Previous work revealed no change in ChAT activity in the sciatic nerve of $d b / d b$ mice (59), and in the current study, mRNA levels for the $M_{1} R$ in the DRG were not affected by STZ-induced diabetes (Supplemental Figure 5). Further studies are required to determine whether endogenous GPCR activity was altered by diabetes. Nonneuronal cells such as keratinocytes also express $M_{1} R$, so that systemic delivery of $M_{1} R$ antagonists or loss of $M_{1} R$ in the $\mathrm{M}_{1} \mathrm{R}-\mathrm{KO}$ mice may impart neuroprotective and regenerative effects via alternative and/or additional pathways. Keratinocytes exhibit a rich cholinergic phenotype with expression of a range of muscarinic and nicotinic components, including $\mathrm{M}_{1} \mathrm{R}$, ChAT, and AChE (60). It has been reported that, during development, keratinocytes produce a cholinergic barrier to penetration of the superficial layers of the epidermis by the plastic peripheral terminals of epidermal sensory neurons (60). Thus, in our studies using systemically delivered $\mathrm{M}_{1} \mathrm{R}$ antagonists in animals, these agents could also operate via blockade of $\mathrm{M}_{1} \mathrm{R}$ activity in keratinocytes or by disruption of the keratinocyte cholinergic barrier. Blockade of $\mathrm{M}_{1} \mathrm{R}$ signaling in satellite cells within the DRG, which then affects neighboring neurons, also cannot be excluded. However, $\mathrm{M}_{1} \mathrm{R}$ expression has not yet been demonstrated in satellite cells, and a study utilizing electron microscopy combined with autoradiography in rat superior cervical ganglia found specific binding of a muscarinic agonist to the $M_{1} R$ in neuronal somata and dendrites and not satellite cells (61). Given the possible range of off-target effects of the antimuscarinic drugs, it was promising that, from a therapeutic standpoint, no side effects were observed. Moreover, none of the drugs in the long term (3- to 4-month treatment protocols) affected the diabetic state, thereby excluding acute or long-term modulation of pancreatic function (Supplemental Tables 1 and 2). Noninvasive and iterative echocardiogram studies in STZ-induced diabetic mice have also been unable to demonstrate alterations in cardiac structure or function (data not shown).

Although the manifestations of peripheral neuropathy can vary between patients with any of the diseases modeled in our studies, there is a growing appreciation that mitochondrial dysfunction contributes to many types of neuropathy by promoting retraction or loss of peripheral sensory terminals and sensory loss (2-4). Sensory neurons exhibit a condensed mitochondrial network, and this is particularly apparent in unmyelinated neurons that require very high rates of ATP production to maintain electrical activity along the whole length of the axon due to the absence of nodes of Ranvier to mediate saltatory conduction $(8,34)$. In human skin biopsies, loss of mitochondrial content in IENF of patients with early signs of neuropathy has been documented (62). Our in vivo studies with pirenzepine-treated type 1 and type 2 diabetic rodents indicate that nerve protection and/ or repair occurred in association with correction of deactivation of AMPK and of multiple indices of mitochondrial dysfunction in the DRG (Figure 5, A-C, and Supplemental Figure 6, C-E). Other factors that augment mitochondrial function, such as ciliary neurotrophic factor and C-terminal inhibitors of heat shock protein 90 , also correct neuropathy in diabetic rodents $(37,38)$. The blockade of muscarinic receptor-mediated inhibition of mitochondrial activity using antimuscarinic drugs may not represent a specific intervention against any one primary pathogenic mechanism and potentially allows broad therapeutic application to all conditions that show diminished energy capacity under stress. Moreover, diminished AMPK activity and mitochondrial complex expression and activity are not unique to the nervous system in diabetes, and 
similar deficits have been reported in mesangial cells of the kidney in diabetic nephropathy (63). Interestingly, a recent drug screen for factors enhancing myelination in models of multiple sclerosis also identified broad spectrum antimuscarinics as potential therapeutics (64). While the animal models of peripheral neuropathy that we studied do not exhibit overt demyelination, it is a feature of the equivalent human diseases that may also be amenable to antimuscarinic therapy.

Peripheral neuropathy is a major, and largely untreated, cause of human morbidity, with huge associated health care costs (65). One particularly encouraging implication of our identification of the endogenous $\mathrm{M}_{1} \mathrm{R}$-mediated suppression of sensory neuron metabolism is that drugs that modulate this process are already in widespread clinical use for other indications. Moreover, the safety profile of antimuscarinic drugs is well characterized, with over 20 years of clinical application for a variety of indications in Europe and the safe use of topical pirenzepine applied to the eye to treat myopia in children (41). The therapeutic application of $M_{1} R$ antagonists suggested by our studies could potentially translate relatively rapidly to clinical use. Nerve conduction slowing is commonly used as an efficacy end point in clinical trials, and this disorder was prevented in diabetic rodents by pirenzepine therapy. Most notably, structural (IENF loss) and functional (thermal hypoalgesia) indices of small fiber neuropathy present in diabetic rodents were both prevented and reversed by antimuscarinic drugs. Since small fiber degeneration develops early in the human disease and can be reliably quantified using a variety of minimal or noninvasive techniques that can be applied iteratively (66-68), future clinical trials of antimuscarinic drugs might feasibly focus on reversal of these early indices of neuropathy. Further, as antimuscarinic drugs were effective in augmenting collateral sprouting in our in vitro assay, this new therapeutic approach may be most effective during the early stages of a dying-back neuropathy prior to overt and/or complete fiber loss.

\section{Methods}

Culture of adult sensory neurons from rats and mice. DRGs from adult male rats or mice (from Central Animal Care, University of Manitoba) were dissociated using previously described methods $(37,69,70)$. Centrifugation through a $15 \%$ BSA column was used to enrich for neurons, as described (71). This procedure removed the vast majority of fibroblasts and Schwann cells; however, a small number of satellite cells approximating $5 \%$ to $10 \%$ of the final culture remained (mostly directly associated with large sensory neurons). Neurons were cultured in defined Hams F12 media in the presence of modified Bottenstein's $\mathrm{N} 2$ supplement without insulin $(0.1 \mathrm{mg} / \mathrm{ml}$ transferrin, $20 \mathrm{nM}$ progesterone, $100 \mu \mathrm{M}$ putrescine, $30 \mathrm{nM}$ sodium selenite, $0.1 \mathrm{mg} / \mathrm{ml} \mathrm{BSA}$; all additives were from Sigma-Aldrich; culture medium was from Life Technologies). In all experiments, the media was also supplemented with a low-dose cocktail of neurotrophic factors (0.1 ng/ml NGF, 1.0 $\mathrm{ng} / \mathrm{ml} \mathrm{GDNF}$, and $0.1 \mathrm{ng} / \mathrm{ml} \mathrm{NT}-3$; all from Promega). The growth factor treatment attempted to mimic the levels of neurotrophic support experienced in vivo by sensory neurons (see Supplemental Figure 1 for rationale). As shown in Figure $2 \mathrm{~F}$ and Supplemental Figure 1, we also used a medium-dose cocktail (0.3 ng/ml NGF, $5 \mathrm{ng} / \mathrm{ml}$ GDNF, $1 \mathrm{ng} /$ $\mathrm{ml} \mathrm{NT-3}$, and $0.1 \mathrm{nM}$ insulin) or a high-dose cocktail (1 ng/ml NGF, 10 $\mathrm{ng} / \mathrm{ml} \mathrm{GDNF}, 10 \mathrm{ng} / \mathrm{ml} \mathrm{NT}-3$, and $1 \mathrm{nM}$ insulin). Age-matched control neurons were cultured in the presence of $10 \mathrm{mM}$ D-glucose and $0.1 \mathrm{nM}$ insulin and diabetic neurons with $25 \mathrm{mM}$ D-glucose and zero insulin. MT7 was purchased from Alomone Labs.

Assessment of total neurite outgrowth. Rat or mouse neurons grown on glass coverslips were fixed with $2 \%$ paraformaldehyde in PBS ( $\mathrm{pH}$ 7.4) for 15 minutes at room temperature and permeabilized with $0.3 \%$ Triton X-100 in PBS for 5 minutes. Cells were then incubated in blocking buffer (Roche) diluted with FBS and 1.0 mM PBS (1:1:3) for 1 hour, then rinsed 3 times with PBS. The primary antibody used was against $\beta$-tubulin isotype III (cat. T8578; 1:1000), which is neuron specific (Sigma Aldrich). Plates were incubated at $4^{\circ} \mathrm{C}$ overnight. The following day, the coverslips were incubated with CY3-conjugated secondary antibodies (Jackson ImmunoResearch Laboratories) for 1 hour at room temperature and then mounted and imaged using a Carl Zeiss Axioscope-2 fluorescence microscope equipped with an AxioCam camera. Random images were captured using Axio-Vision4.8 software. Alternatively, in neurons transfected with GFP-expressing vectors, random images of the GFP signal were captured. Quantification of total neurite outgrowth was performed by measuring the mean pixel area of captured images using Image J software (NIH) adjusted for the cell body signal. All values were adjusted for neuronal number $(38,72)$. In this culture system, the level of total neurite outgrowth has been validated to be directly related to an arborizing form of axonal plasticity and homologous to collateral sprouting in vivo (73).

Real-time intracellular calcium imaging. For acute measurements, as shown in Figure 1, F-H, neurons were cultured in 96-well glass-bottom dishes overnight and then loaded with calciumsensitive dye using the Fluo-4 NW (no wash) Kit from Thermo Fisher Scientific. The dish was placed in a Cellomics Arrayscan-VTI HCS Reader (Thermo Fisher Scientific) with liquid delivery attachment. Baseline signals were collected over 1 to 2 minutes; then drugs were added, after which images were collected over 80 seconds. At least 54-78 neurons were imaged in each well over this period. The data are presented as averaged intensity of fluo- 4 fluorescence. Cloning and expression of M1R. The full-length cDNA of $\mathrm{M}_{1} \mathrm{R}$ was amplified using the forward and reverse primers (ATGAACACCTCAGTGCCCCCTGC and TTAGCATTGGCGGGAGGGGGTG, respectively) from total RNA extracted from C57BL/J mouse brain tissue. The $M 1 R$-cDNA was subsequently cloned in $\mathrm{pEGFP-C1}$ vector (Promega) at the Xho1 and SacII restriction sites. The pEGFP-M R plasmid was transfected into adult primary rat DRG neurons using Amaxa Rat Neuron Nucleofection Reagent (VPG-01003) and cultured as described above. The neurons were harvested 48 hours after transfection, and cell lysates were prepared for Western blot, or neurons were fixed in $2 \%$ paraformaldehyde. Western blot was immunoblotted using antibodies to GFP (ab-290, Abcam) and $\mathrm{M}_{1} \mathrm{R}$ (AMR-001, Alomone Labs) to detect $\mathrm{M}_{1} \mathrm{R}-\mathrm{GFP}$ fusion protein.

Measurement of mitochondrial respiration in DRG neurons from mice and rats. An XF24 Analyzer (Seahorse Biosciences) was used to measure neuronal bioenergetic function. The XF24 creates a transient 7- $\mu \mathrm{l}$ chamber in specialized 24-well microplates that allows for OCR to be monitored in real time. Culture medium was changed 1 hour before the assay to unbuffered DMEM ( $\mathrm{pH}$ 7.4) supplemented with $1 \mathrm{mM}$ pyruvate and $10 \mathrm{mM}$ D-glucose. Neuron density in the range of 2,500-5,000 cells per well gave linear OCR. Oligomycin $(1 \mu \mathrm{M})$, carbonyl cyanideptrifluorocarbonyl-cyanide methoxyphenyl hydrazone (FCCP) (range of 0.1 to $1.0 \mu \mathrm{M})$, and rotenone $(1 \mu \mathrm{M})$ plus antimycin $\mathrm{A}(1 \mu \mathrm{M})$ was inject- 
ed sequentially through ports in the Seahorse Flux Pak cartridges. Each loop was started with mixing for 3 minutes, then delayed for 2 minutes and OCR measured for 3 minutes. This allowed determination of the basal level of oxygen consumption, the amount of oxygen consumption linked to ATP production, the level of non-ATP-linked oxygen consumption (proton leak), the maximal respiration capacity, and the nonmitochondrial oxygen consumption $(74,75)$. Oligomycin inhibits the ATP synthase, leading to a build-up of the proton gradient that inhibits electron flux and reveals the state of coupling efficiency. Uncoupling of the respiratory chain by FCCP injection reveals the maximal capacity to reduce oxygen. Finally, rotenone plus antimycin A was injected to inhibit the flux of electrons through complexes I and III, and thus no oxygen was further consumed at cytochrome $c$ oxidase. The remaining OCR determined after this intervention is primarily nonmitochondrial. Following OCR measurement, the cells were immediately fixed and double-stained for $\beta$-tubulin III and activating transcription factor 3 (ATF3), which specifically labels nuclei of axotomized sensory neurons. The plates were then inserted into a Cellomics Arrayscan-VTI HCS Reader (Thermo Scientific) equipped with Cellomics Arrayscan-VTI software to determine total neuronal number in each well. Data are expressed as OCR in pmoles/min for 1,000 cells. For mitochondria isolated from rat DRG, oxygen consumption was determined at $37^{\circ} \mathrm{C}$ using the OROBOROS Oxygraph-2K (OROBOROS Instruments $\mathrm{GmbH}$ ) (76). Isolated mitochondria from lumbar DRG were resuspended in $\mathrm{KCl}$ medium (80 $\mathrm{mM} \mathrm{KCl}, 10 \mathrm{mM}$ Tris- $\mathrm{HCl}, 3 \mathrm{mM} \mathrm{MgCl}, 1 \mathrm{mM}$ EDTA, $5 \mathrm{mM}$ potassium phosphate, $\mathrm{pH}$ 7.4). Various substrates and inhibitors for mitochondrial respiratory chain complexes were used as described in Supplemental Figure 6, D and E. OROBOROS DatLab software was used to calculate the OCRs and for the graphic presentation of experimental data.

Protein expression in DRG. DRG homogenate or lysate from DRG cell culture $(7.5-10.0 \mu \mathrm{g})$ was resolved on a 10\% SDS-PAGE gel $(8 \%$ for phosphorylated acetyl coenzyme A carboxylase [P-ACC]) and electroblotted onto nitrocellulose membrane. Blots were then blocked in $5 \%$ nonfat milk containing 0.05\% Tween-20, rinsed in TBS then PBS ( $\mathrm{pH}$ 7.4), and incubated with antibodies to the following proteins: phosphorylated AMPK (Thr172, p-AMPK; cat. SC3352; 1:500, Santa Cruz Biotechnology Inc.; Cell Signaling Technology), total AMPK (T-AMPK; cat. SC25792; 1:500, Santa Cruz Biotechnology Inc.), PGC$1 \alpha$ (cat SC13067; 1:500, Santa Cruz Biotechnology Inc.), p-ACC (cat. ab31931; 1:2000, Abcam), CaMKK $\beta$ (cat. SC100364; 1:1000, Santa Cruz Biotechnology Inc.), CaMKK $\alpha$ (cat. SC17827 [F-2]; 1:1000, Santa Cruz Biotechnology Inc.), cytochrome $c$ oxidase subunit 4 (COX IV; cat. MS407; 1:1000, Mitoscience), and NADH dehydrogenase (ubiquinone) iron-sulfur protein 3 (NDUFS3; cat. MS110; 1:1000, Mitoscience). Total extracellular regulated protein kinase (T-ERK; cat. SC93 [C-16]; 1:2000, Santa Cruz Biotechnology Inc.) was probed as a loading control (previous studies have shown that the expression of this protein does not change in intact DRG or cultures from diabetic rats). The blots were rinsed, incubated in Western blotting Luminol Reagent (Santa Cruz Biotechnology Inc.), Bio-Rad Clarity Western ECL substrate, or ECL Advanced (GE Healthcare) and imaged using a Bio-Rad or Fluor-S analyzer or ChemiDoc MP (Bio-Rad).

Luciferase reporter constructs for PGC-1 $\alpha$ and cell transfection. Reporter plasmids with the PGC- $1 \alpha$ promoter upstream from luciferase were donated by Michael Czubryt (University of Manitoba). Rat DRG cells $\left(30 \times 10^{3}\right)$ were transfected in triplicate with $1.8 \mu$ g of PGC- $1 \alpha$ Luc-promoter plasmid DNA and $0.2 \mu \mathrm{g}$ of pCMV-Renilla (Promega) using the Amaxa Nucleofector Electroporation Kit for low numbers of cells according to the manufacturer's instructions (ESBE Scientific). Cells were lysed using passive lysis buffer provided with the DualLuciferase Reporter Assay System (Promega). Luciferase activity was measured using a luminometer (model LMAXII; Molecular Devices). 20 $\mu \mathrm{l}$ of each sample was loaded in a 96-well plate and was mixed with 100 $\mu$ l of Luciferase Assay Reagent II, and firefly luciferase activity was first recorded. Then, $100 \mu \mathrm{l}$ of Stop-and-Glo Reagent (Promega) was added, and Renilla luciferase activity was measured. All values were adjusted to Renilla luciferase activity and normalized to control plasmid pGL3 levels. CC, a specific inhibitor of AMPK (77), was obtained from Abcam.

Viral transduction of AMPK mutants in cultured sensory neurons. Adult sensory neurons from control or diabetic rats maintained in the presence of a low-dose cocktail of neurotrophic factors were infected with adenovirus carrying dominant negative mutants of AMPK $\alpha 1$ or AMPK $\alpha 2$ subunits (DN1 or DN2) or constitutively active AMPK (ad-AMPK-CA), respectively. The ad-AMPK-CA and dominant negative adenoviral constructs were delivered at $20 \mathrm{PFU} / \mathrm{cell}$, and the control adenoviral construct was delivered at $10 \mathrm{PFU} /$ cell. Cultures were allowed to attach/grow for 1 day and were incubated with adenovirus for 3 hours, and the media was changed. Neurite outgrowth was determined in GFP-positive neurons 48 hours after infection. The constructs were gifts from Jason Dyck (University of Alberta, Edmonton, Alberta, Canada) (78).

Respiratory complex activities in mouse DRG. Measurements of enzymatic activities of respiratory complexes from mouse DRG homogenates were performed using a temperature-controlled Ultrospec 2100 UV-visible spectrophotometer equipped with Biochrom Swift II software (Biopharmacia Biotech) as previously described (11).

Animals. Studies were performed in Sprague-Dawley rats (Harlan) and Swiss Webster, C57BL/6 (stock 000664), C57BLKS (stock 000662), and BKS.Cg-Dock $7^{\mathrm{m}}+/+$ Lepr $^{\mathrm{db}} / \mathrm{J}$ (stock 000642: commonly called $d b / d b$ ) mice (all Jackson Laboratories) or $\mathrm{M}_{1} \mathrm{R}$ knockout mice on a C57BL/6 background (line 1784; Taconic Biosciences Inc.) (79). In all but the spontaneously diabetic $d b / d b$ mice, type 1 diabetes was induced by injection of STZ (from Sigma-Aldrich) in $0.9 \%$ saline after overnight fast at a single dose of $50-60 \mathrm{mg} / \mathrm{kg}$ for female rats, $75 \mathrm{mg} / \mathrm{kg}$ for male rats, or $90-100 \mathrm{mg} / \mathrm{kg}$ on 2 consecutive days for mice. Blood glucose levels were confirmed 4 to 7 days later in samples obtained by tail prick and measured using a strip-operated reflectance meter (One Touch Ultra, LifeScan Inc.). Persistence of diabetic status was confirmed at the end of each study (see Supplemental Tables 1 and 2) by recording body weight, blood glucose, and in select studies, plasma insulin concentration (Ultra Mouse Insulin ELISA kit, Crystal Chem Inc.) and HbA1c (A1CNow Test Kit, Bayer Healthcare). Paclitaxel neuropathy was induced by injection (5.0 mg/kg i.p.) on days 1, 3, 5, and 7 of the study (80). DCA neuropathy was induced by daily injection $(1.0 \mathrm{~g} / \mathrm{kg}$ i.p.) throughout the study $(43,81)$. Local exposure to gp120 (product 1021, ImmunoDX) was used to model HIV neuropathy (44). Adult female Swiss Webster mice received 1 daily eye drop containing vehicle alone $(20 \mu \mathrm{l}$ of $0.1 \mathrm{M}$ sodium phosphate buffer) or gp120 $(2.5 \mathrm{ng} / \mathrm{ml}$ in vehicle) for 10 weeks. In all studies, animals were randomly assigned to groups, and all animals and their derived tissues were coded to ensure blinding of investigators during behavioral, physiological, and histological assays. Pirenzepine (Sigma-Aldrich) was given at $0.1-10 \mathrm{mg} / \mathrm{kg}$ s.c. 5 times weekly, and VU0255035 (a gift from Vanderbilt Center for Neuroscience Drug Discovery, Franklin, Tennessee) was given at 10 
mg/kg i.p. 5 times weekly. MT7 (product M-200, Alomone Labs) was given as eye drops ( $20 \mu \mathrm{l}$ of $25 \mathrm{ng} / \mathrm{ml}$ solution in $0.1 \mathrm{M}$ sodium phosphate buffer) either once daily from the onset of gp120 exposure or 3 times daily starting after 5 weeks of gp120 exposure.

Behavioral tests. Hind-paw withdrawal responses to von Frey filaments (50\% paw withdrawal threshold in gram of force applied) and radiant heat (latency to withdrawal in seconds) and also paw flinching following injection of $50 \mu \mathrm{l} 0.5 \%$ formalin were measured in conscious unrestrained animals $(82,83)$.

Electrophysiology. Electrophysiological parameters were determined as previously described in multiple papers $(84,85)$. Animals were anesthetized with isoflurane and stimulating electrodes placed at the sciatic notch and Achilles tendon of the left hind limb, with recording electrodes placed in the interosseus muscles of the ipsilateral foot. Nerve temperature was maintained at $37^{\circ} \mathrm{C}$ and the nerve stimulated by single-square wave pulses applied first to the notch and then the tendon. Peak-peak latency of the resulting $\mathrm{M}$ or $\mathrm{H}$ waves was used to derive MNCV and sciatic sensory nerve-conduction velocity (SNCV), respectively, using the distance between stimulating electrodes. NCV was measured in triplicate and the median used to represent NCV of the animal.

IENF quantification. The plantar dermis and epidermis of the hind paw was removed and added to $4 \%$ paraformaldehyde. Tissue was processed to paraffin blocks, cut as $6-\mu \mathrm{m}$ sections, and immunostained using an antibody to PGP 9.5 (cat. 7863-0504; 1:1000, AbD Serotec); the number of immunoreactive IENF profiles was quantified under blinded conditions by light microscopy and normalized to length of the dermal/ epidermal junction (86).

Corneal confocal microscopy. Corneal nerves of the subbasal nerve plexus were imaged in anesthetized mice using a Heidelberg Retina Tomograph 3 with Rostock Cornea Module (Heidelberg Engineering), and occupancy of 5 consecutive images ( $2 \mu \mathrm{m}$ intervals) per animal was calculated using an $8 \times 8$ grid (Figure 8 ) as described elsewhere (87).

Statistics. Data are expressed as mean \pm SEM and individual data points shown in scatter dot plots when $n$ is greater than 3 . Where appropriate, data were subjected to unpaired 2-tailed Student's $t$ test, 1-way ANOVA with post-hoc comparisons using Tukey's or Dunnett's post-hoc tests, or 2-way ANOVA with repeat measures followed by Dunnett's post-hoc test. GraphPad Prism software was used to perform statistical analysis.

Study approval. All animal procedures were approved by the University of Manitoba Animal Care Committee (overseen by the Com- mittee on Animal Care) using Canadian Council of Animal Care rules or the Institutional Animal Care and Use Committee at UCSD.

\section{Author contributions}

$\mathrm{KF}, \mathrm{AG}, \mathrm{TMZ}$, and DRS established, maintained, treated, and performed behavioral assays on groups of rats and mice. LT, RVDP, MGS, and DRS performed primary neuron cell culture, Western blotting, and immunocytochemistry. RVDP carried out the initial drug screen and analyzed calcium signals in cultured neurons. SKR performed mitochondrial enzymatic activities and Seahorse and Oroboros analysis of mitochondrial function. AS carried out gene reporter and adenoviral infection studies. MGS generated the GFP-M $\mathrm{M}_{1} \mathrm{R}$ and Halo constructs, reverse-transcriptase PCR (RT-PCR), siRNA knockdown, 2D gel and isoelectric focusing, and time-lapse calcium imaging. KF, JO, AG, NM, and CGJ performed morphometric, electrophysiological, and biochemical assays. LT, RVP, DRS, MGS, AS, SKRC, KF, and CGJ analyzed data. JW provided $M_{1} R$ knockout mice and edited the paper. DRS, MGS, and CGJ designed experiments. PF and NAC designed experiments, analyzed data, and wrote and edited the paper.

\section{Acknowledgments}

This work was funded by grants 14-2006-341, 17-2008-1047, and 17-2011-252 from the JDRF and grants RPA-124953 and MOP130282 from the Canadian Institutes of Health Research (to PF), grants DK057629, NS081082, DP3DK094346-01 (sub-award), and DK076169 (sub-award 23789-5) from the NIH (to NAC) and NIH grant AG039736 (to CGJ). We are grateful to St. Boniface Hospital Research Foundation for support. We thank Michael Czubryt (University of Manitoba) for reporter plasmids, Jason Dyck (University of Alberta) for adenoviral constructs, Jeffrey Conn (Vanderbilt Center for Neuroscience Drug Discovery) for gifts of VU0255035, and Nick Anderson, Alex Marquez, Dwane Morrow, Allison Quach, Mahalakshmi Razdan, Graziella Te, and Vanessa Thompson for expert technical assistance.

Address correspondence to: Paul Fernyhough, R4046 - 351 Taché Avenue, St. Boniface Hospital Research Centre, Winnipeg, Manitoba, R2H 2A6, Canada. Phone: 204.235.3692; E-mail: pfernyhough@sbrc.ca.
1. Albers KM, Davis BM. The skin as a neurotrophic organ. Neuroscientist. 2007;13(4):371-382.

2. Bennett GJ, Doyle T, Salvemini D. Mitotoxicity in distal symmetrical sensory peripheral neuropathies. Nat Rev Neurol. 2014;10(6):326-336.

3. Cashman CR, Höke A. Mechanisms of distal axonal degeneration in peripheral neuropathies. Neurosci Lett. 2015;596:33-50.

4. Chowdhury SK, Smith DR, Fernyhough P. The role of aberrant mitochondrial bioenergetics in diabetic neuropathy. Neurobiol Dis. 2013;51:56-65.

5. Bernstein BW, Bamburg JR. Actin-ATP hydrolysis is a major energy drain for neurons. J Neurosci. 2003;23(1):1-6.

6. Harris JJ, Jolivet R, Attwell D. Synaptic energy use and supply. Neuron. 2012;75(5):762-777.

7. Li Z, Okamoto K, Hayashi Y, Sheng M. The importance of dendritic mitochondria in the morphogenesis and plasticity of spines and synapses. Cell. 2004;119(6):873-887.

8. Wang SS, et al. Functional trade-offs in white matter axonal scaling. J Neurosci. 2008;28(15):4047-4056.

9. Chen H, Chan DC. Critical dependence of neurons on mitochondrial dynamics. Curr Opin Cell Biol. 2006;18(4):453-459.

10. Breathnach AS. Electron microscopy of cutaneous nerves and receptors. J Invest Dermatol. 1977;69(1):8-26.

11. Roy Chowdhury SK, et al. Impaired adenosine monophosphate-activated protein kinase signalling in dorsal root ganglia neurons is linked to mitochondrial dysfunction and peripheral neuropathy in diabetes. Brain. 2012;135(Pt 6):1751-1766.

12. Feige JN, Auwerx J. Transcriptional coregulators in the control of energy homeostasis. Trends Cell Biol. 2007;17(6):292-301.

13. Chowdhury SK, Dobrowsky RT, Fernyhough P. Nutrient excess and altered mitochondrial proteome and function contribute to neurodegeneration in diabetes. Mitochondrion. 2011;11(6):845-854.

14. Dasgupta B, Milbrandt J. Resveratrol stimulates AMP kinase activity in neurons. Proc Natl Acad Sci USA. 2007;104(17):7217-7222.

15. Samuel MA, et al. LKB1 and AMPK regulate synaptic remodeling in old age. Nat Neurosci. 2014;17(9):1190-1197.

16. Tao K, Matsuki N, Koyama R. AMP-activated protein kinase mediates activity-dependent axon branching by recruiting mitochondria to axon. Dev Neurobiol. 2014;74(6):557-573.

17. St-Pierre J, et al. Suppression of reactive 
oxygen species and neurodegeneration by the PGC-1 transcriptional coactivators. Cell. 2006;127(2):397-408.

18. Shin JH, et al. PARIS (ZNF746) repression of PGC-1 $\alpha$ contributes to neurodegeneration in Parkinson's disease. Cell. 2011;144(5):689-702.

19. Kamiya H, Zhang W, Sima AA. Degeneration of the Golgi and neuronal loss in dorsal root ganglia in diabetic BioBreeding/Worcester rats. Diabetologia. 2006;49(11):2763-2774.

20. Erskine L, McCaig CD. Growth cone neurotransmitter receptor activation modulates electric field-guided nerve growth. Dev Biol. 1995;171(2):330-339.

21. Young SH, Poo MM. Spontaneous release of transmitter from growth cones of embryonic neurones. Nature. 1983;305(5935):634-637.

22. Tata AM, Cursi S, Biagioni S, Augusti-Tocco G. Cholinergic modulation of neurofilament expression and neurite outgrowth in chick sensory neurons. J Neurosci Res. 2003;73(2):227-234.

23. Yang $\mathrm{H}$, Kunes $\mathrm{S}$. Nonvesicular release of acetylcholine is required for axon targeting in the Drosophila visual system. Proc Natl Acad Sci USA. 2004;101(42):15213-15218.

24. Bernardini N, Tomassy GS, Tata AM, Augusti-Tocco G, Biagioni S. Detection of basal and potassium-evoked acetylcholine release from embryonic DRG explants. J Neurochem. 2004;88(6):1533-1539.

25. Bellier JP, Kimura H. Acetylcholine synthesis by choline acetyltransferase of a peripheral type as demonstrated in adult rat dorsal root ganglion. J Neurochem. 2007;101(6):1607-1618.

26. Bernardini N, Levey AI, Augusti-Tocco G. Rat dorsal root ganglia express $\mathrm{m} 1-\mathrm{m} 4$ muscarinic receptor proteins. J Peripher Nerv Syst. 1999;4(34):222-232.

27. Tata AM, Vilaró MT, Mengod G. Muscarinic receptor subtypes expression in rat and chick dorsal root ganglia. Brain Res Mol Brain Res. 2000;82(1-2):1-10.

28. Hadimani MB, et al. Guaifenesin derivatives promote neurite outgrowth and protect diabetic mice from neuropathy. J Med Chem. 2013;56(12):5071-5078.

29. Birdsall NJ, et al. Muscarinic receptor subclasses: evidence from binding studies. Adv Biochem Psychopharmacol. 1983;37:323-329.

30. Sheffler DJ, et al. A novel selective muscarinic acetylcholine receptor subtype 1 antagonist reduces seizures without impairing hippocampus-dependent learning. Mol Pharmacol. 2009;76(2):356-368.

31. Alabaster VA. Discovery \& development of selective M3 antagonists for clinical use. Life Sci. 1997;60(13-14):1053-1060.

32. Lazareno S, Birdsall NJ. Pharmacological characterization of acetylcholine-stimulated [35S]-GTP gamma $S$ binding mediated by human muscarinic m1-m4 receptors: antagonist studies. $\mathrm{Br} \mathrm{J}$ Pharmacol.1993;109(4):1120-1127.

33. Max SI, Liang JS, Potter LT. Purification and properties of m1-toxin, a specific antagonist of $\mathrm{m} 1$ muscarinic receptors. J Neurosci. 1993;13(10):4293-4300.

34. Perkins GA, Ellisman MH. Mitochondrial configurations in peripheral nerve suggest differential
ATP production. J Struct Biol. 2011;173(1):117-127.

35. Zherebitskaya E, Akude E, Smith DR, Fernyhough P. Development of selective axonopathy in adult sensory neurons isolated from diabetic rats: role of glucose-induced oxidative stress. Diabetes. 2009;58(6):1356-1364.

36. Ma J, et al. Heat shock protein 70 is necessary to improve mitochondrial bioenergetics and reverse diabetic sensory neuropathy following KU-32 therapy.J Pharmacol Exp Ther. 2014;348(2):281-292.

37. Urban MJ, Pan P, Farmer KL, Zhao H, Blagg BS, Dobrowsky RT. Modulating molecular chaperones improves sensory fiber recovery and mitochondrial function in diabetic peripheral neuropathy. Exp Neurol. 2012;235(1):388-396.

38. Saleh A, et al. Ciliary neurotrophic factor activates NF- $\mathrm{KB}$ to enhance mitochondrial bioenergetics and prevent neuropathy in sensory neurons of streptozotocin-induced diabetic rodents. Neuropharmacology. 2013;65:65-73.

39. Cantó C, Auwerx J. PGC-1alpha, SIRT1 and AMPK, an energy sensing network that controls energy expenditure. Curr Opin Lipidol. 2009;20(2):98-105.

40. Biessels GJ, et al. Phenotyping animal models of diabetic neuropathy: a consensus statement of the diabetic neuropathy study group of the EASD (Neurodiab). J Peripher Nerv Syst. 2014;19(2):77-87.

41. Siatkowski RM, et al. Two-year multicenter, randomized, double-masked, placebo-controlled, parallel safety and efficacy study of $2 \%$ pirenzepine ophthalmic gel in children with myopia. JAAPOS. 2008;12(4):332-339.

42. Hammer R, Koss FW. The pharmacokinetic profile of pirenzepine. Scand J Gastroenterol Suppl. 1979;57:1-6.

43. Kankotia S, Stacpoole PW. Dichloroacetate and cancer: new home for an orphan drug? Biochim Biophys Acta. 2014;1846(2):617-629.

44. Melli G, Keswani SC, Fischer A, Chen W, Höke A. Spatially distinct and functionally independent mechanisms of axonal degeneration in a model of HIV-associated sensory neuropathy. Brain. 2006;129(Pt 5):1330-1338.

45. Wess J. Molecular biology of muscarinic acetylcholine receptors. Crit Rev Neurobiol. 1996;10(1):69-99.

46. Bakker G, et al. 123I-iododexetimide preferentially binds to the muscarinic receptor subtype M1 in vivo. J Nucl Med. 2015;56(2):317-322.

47. Pavia J, Marquez E, Laukkonen S, Martos F, Gómez A, Sánchez de la Cuesta F. M1 and M3 muscarinic receptor subtypes in rat forebrain. Methods Find Exp Clin Pharmacol. 1991;13(10):653-660.

48. Hanada K, Kishimoto S, Bellier JP, Kimura H. Peripheral choline acetyltransferase in rat skin demonstrated by immunohistochemistry. Cell Tissue Res. 2013;351(3):497-510.

49. Corsetti V, Mozzetta C, Biagioni S, Augusti Tocco G, Tata AM. The mechanisms and possible sites of acetylcholine release during chick primary sensory neuron differentiation. Life Sci. 2012;91(15-16):783-788.

50. Brown DA, Passmore GM. Neural KCNQ (Kv7) channels. Br J Pharmacol. 2009;156(8):1185-1195.
51. Passmore GM, et al. KCNQ/M currents in sensory neurons: significance for pain therapy. JNeurosci. 2003;23(18):7227-7236.

52. Hawley SA, et al. Calmodulin-dependent protein kinase kinase-beta is an alternative upstream kinase for AMP-activated protein kinase. Cell Metab. 2005;2(1):9-19.

53. Persson AK, Kim I, Zhao P, Estacion M, Black JA, Waxman SG. Sodium channels contribute to degeneration of dorsal root ganglion neurites induced by mitochondrial dysfunction in an in vitro model of axonal injury. J Neurosci. 2013;33(49):19250-19261.

54. Press C, Milbrandt J. Nmnat delays axonal degeneration caused by mitochondrial and oxidative stress. J Neurosci. 2008;28(19):4861-4871.

55. Zhou B, Yu P, Lin MY, Sun T, Chen Y, Sheng ZH. Facilitation of axon regeneration by enhancing mitochondrial transport and rescuing energy deficits. JCell Biol. 2016;214(1):103-119.

56. Diaz-Ruiz R, Rigoulet M, Devin A. The Warburg and Crabtree effects: On the origin of cancer cell energy metabolism and of yeast glucose repression. Biochim Biophys Acta. 2011;1807(6):568-576.

57. Akkina SK, Patterson CL, Wright DE. GDNF rescues nonpeptidergic unmyelinated primary afferents in streptozotocin-treated diabetic mice. Exp Neurol. 2001;167(1):173-182.

58. Christianson JA, Riekhof JT, Wright DE. Restorative effects of neurotrophin treatment on diabetes-induced cutaneous axon loss in mice. Exp Neurol. 2003;179(2):188-199.

59. Calcutt NA, Willars GB, Tomlinson DR. Axonal transport of choline acetyltransferase and 6phosphofructokinase activities in genetically diabetic mice. Muscle Nerve. 1988;11(12):1206-1210.

60. Grando SA, Pittelkow MR, Schallreuter $\mathrm{KU}$. Adrenergic and cholinergic control in the biology of epidermis: physiological and clinical significance. J Invest Dermatol. 2006;126(9):1948-1965.

61. Ramcharan EJ, Matthews MR. Autoradiographic localization of functional muscarinic receptors in the rat superior cervical sympathetic ganglion reveals an extensive distribution over nonsynaptic surfaces of neuronal somata, dendrites and nerve endings. Neuroscience. 1996;71(3):797-832.

62. Casanova-Molla J, et al. Mitochondrial loss indicates early axonal damage in small fiber neuropathies. J Peripher Nerv Syst. 2012;17(2):147-157.

63. Sharma K. Mitochondrial hormesis and diabetic complications. Diabetes. 2015;64(3):663-672.

64. Mei F, et al. Micropillar arrays as a high-throughput screening platform for therapeutics in multiple sclerosis. Nat Med. 2014;20(8):954-960.

65. McInnes AD. Diabetic foot disease in the United Kingdom: about time to put feet first. J Foot Ankle Res. 2012;5(1):26.

66. Breiner A, Lovblom LE, Perkins BA, Bril V. Does the prevailing hypothesis that small-fiber dysfunction precedes large-fiber dysfunction apply to type 1 diabetic patients? Diabetes Care. 2014;37(5):1418-1424.

67. Malik RA, et al. Small fibre neuropathy: role in the diagnosis of diabetic sensorimotor polyneuropathy. Diabetes Metab Res Rev. 2011;27(7):678-684 68. Smith AG, Ramachandran P, Tripp S, Singleton 
JR. Epidermal nerve innervation in impaired glucose tolerance and diabetes-associated neuropathy. Neurology. 2001;57(9):1701-1704.

69. Huang TJ, Sayers NM, Verkhratsky A, Fernyhough P. Neurotrophin-3 prevents mitochondrial dysfunction in sensory neurons of streptozotocin-diabetic rats. Exp Neurol. 2005;194(1):279-283.

70. Gardiner NJ, Fernyhough P, Tomlinson DR, Mayer U, von der Mark H, Streuli CH. Alpha7 integrin mediates neurite outgrowth of distinct populations of adult sensory neurons. Mol Cell Neurosci. 2005;28(2):229-240.

71. Gavazzi I, Kumar RD, McMahon SB, Cohen J. Growth responses of different subpopulations of adult sensory neurons to neurotrophic factors in vitro. Eur J Neurosci. 1999;11(10):3405-3414.

72. Fernyhough P, Willars GB, Lindsay RM, Tomlinson DR. Insulin and insulin-like growth factor I enhance regeneration in cultured adult rat sensory neurones. Brain Res. 1993;607(1-2):117-124.

73. Smith DS, Skene JH. A transcription-dependent switch controls competence of adult neurons for distinct modes of axon growth. J Neurosci. 1997;17(2):646-658.

74. Brand MD, Nicholls DG. Assessing mitochondrial dysfunction in cells. Biochem J.
2011;435(2):297-312.

75. Hill BG, Dranka BP, Zou L, Chatham JC, Darley-Usmar VM. Importance of the bioenergetic reserve capacity in response to cardiomyocyte stress induced by 4-hydroxynonenal. Biochem $\mathrm{J}$. 2009;424(1):99-107.

76. Chowdhury SK, Gemin A, Singh G. High activity of mitochondrial glycerophosphate dehydrogenase and glycerophosphate-dependent ROS production in prostate cancer cell lines. Biochem Biophys Res Commun. 2005;333(4):1139-1145.

77. Zhou G, et al. Role of AMP-activated protein kinase in mechanism of metformin action. JClin Invest. 2001;108(8):1167-1174.

78. Jacobs RL, Lingrell S, Dyck JR, Vance DE. Inhibition of hepatic phosphatidylcholine synthesis by 5-aminoimidazole-4-carboxamide-1-beta-4ribofuranoside is independent of AMP-activated protein kinase activation. J Biol Chem. 2007;282(7):4516-4523.

79. Miyakawa T, Yamada M, Duttaroy A, Wess J. Hyperactivity and intact hippocampusdependent learning in mice lacking the M1 muscarinic acetylcholine receptor. J Neurosci. 2001;21(14):5239-5250.

80. Matsumoto M, Inoue M, Hald A, Xie W, Ueda H. Inhibition of paclitaxel-induced A-fiber hyper- sensitization by gabapentin. JPharmacol Exp Ther. 2006;318(2):735-740.

81. Calcutt NA, et al. Peripheral neuropathy in rats exposed to dichloroacetate. J Neuropathol Exp Neurol. 2009;68(9):985-993.

82. Calcutt NA. Experimental models of painful diabetic neuropathy. JNeurol Sci. 2004;220(1-2):137-139.

83. Ramos KM, Jiang Y, Svensson CI, Calcutt NA. Pathogenesis of spinally mediated hyperalgesia in diabetes. Diabetes. 2007;56(6):1569-1576.

84. Calcutt NA, et al. Therapeutic efficacy of sonic hedgehog protein in experimental diabetic neuropathy. JClin Invest. 2003;111(4):507-514.

85. Mizisin AP, Vu Y, Shuff M, Calcutt NA. Ciliary neurotrophic factor improves nerve conduction and ameliorates regeneration deficits in diabetic rats. Diabetes. 2004;53(7):1807-1812.

86. Beiswenger KK, Calcutt NA, Mizisin AP. Epidermal nerve fiber quantification in the assessment of diabetic neuropathy. Acta Histochem. 2008;110(5):351-362.

87. Chen DK, Frizzi KE, Guernsey LS, Ladt K, Mizisin AP, Calcutt NA. Repeated monitoring of corneal nerves by confocal microscopy as an index of peripheral neuropathy in type-1 diabetic rodents and the effects of topical insulin.J Peripher Nerv Syst. 2013;18(4):306-315. 